NBER WORKING PAPER SERIES

\title{
FLAGSHIP ENTRY IN ONLINE MARKETPLACES
}

\author{
Ginger Zhe Jin \\ Zhentong Lu \\ Xiaolu Zhou \\ Lu Fang \\ Working Paper 29239 \\ http://www.nber.org/papers/w29239
NATIONAL BUREAU OF ECONOMIC RESEARCH
1050 Massachusetts Avenue \\ Cambridge, MA 02138
}

September 2021, Revised May 2022

\begin{abstract}
We are grateful to the anonymous e-commerce platform for various support on this project. We thank Qihong Liu, Shane Greenstein, Feng Zhu, Alexander MacKay, Garrett Johnson, Chiara Farronato, Larry White, Yossi Spiegel, Michael Ward, Michael Baye, Panle Barwick, Robert Porter, Lingfang Li and other participants at Harvard Business School Digital Initiative seminar, Bank of Canada BBL seminar, the Virtual Digital Economy seminar, Renmin University, the 2021 Penn State-Cornell conference, the 2021 APIOC conference, and Boston University for constructive comments. Some of us were a consultant or an employee for the studied platform at the beginning of the project. The paper only reflects the opinion of the authors, and not the opinion of any organizations. All rights reserved; all errors are ours. The views expressed herein are those of the authors and do not necessarily reflect the views of the National Bureau of Economic Research.
\end{abstract}

At least one co-author has disclosed additional relationships of potential relevance for this research. Further information is available online at http://www.nber.org/papers/w29239.ack

NBER working papers are circulated for discussion and comment purposes. They have not been peer-reviewed or been subject to the review by the NBER Board of Directors that accompanies official NBER publications.

(C) 2021 by Ginger Zhe Jin, Zhentong Lu, Xiaolu Zhou, and Lu Fang. All rights reserved. Short sections of text, not to exceed two paragraphs, may be quoted without explicit permission provided that full credit, including $(\odot$ notice, is given to the source. 
Flagship Entry in Online Marketplaces

Ginger Zhe Jin, Zhentong Lu, Xiaolu Zhou, and Lu Fang

NBER Working Paper No. 29239

September 2021, Revised May 2022

JEL No. D4,L1,L8

\section{ABSTRACT}

In this paper, we empirically study how flagship entry in an online marketplace affects consumers, the platform, and various sellers on the platform. We find flagship entry may benefit consumers by expanding the choice set, by intensifying price competition within the entry brand, and by improving consumer perception for parts of the platform. In the meantime, flagship entry cannibalizes the sales of same-brand sellers, while other brands may gain as the buyer base expands on the platform. Counterfactual simulation suggests that flagship entry improves the gross merchandise value (GMV) of the platform and overall consumer welfare in most cases.

Ginger Zhe Jin

University of Maryland

Department of Economics

College Park, MD 20742-7211

and NBER

ginger@umd.edu

Zhentong Lu

Bank of Canada

234 Wellington St. W.

Ottawa, ON K1A 0G9

Canada

zlu@bankofcanada.ca
Xiaolu Zhou

Xiamen University

D239 Economic Building

422 Siming South Rd, Siming, Fujian

China

xiaoluzhou2008@gmail.com

Lu Fang

The Rural Development Academy

866 Yuhangtang Rd.

West Lack District

Hangzhou, Zhej 310058

P.R.China

fl_fanglu@zju.edu.cn 


\section{Introduction}

As the internet penetrates the economy, its impact on retail is arguably the most important for millions of consumers. Contrast to a popular view that e-commerce may overtake and displace traditional retail, the boundary of online and offline retail has become ever blurry. For example, some specialty brands find it attractive to sell in a virtual mall despite their own network of offline stores and access to traditional retailers, while other brands prefer offline channels or their own websites. ${ }^{1}$ Some brands even use legal fights to block others from selling their brands at online marketplaces. ${ }^{2}$ A deep dive into the relationship between brands and online marketplaces is necessary if one wants to fully understand how e-commerce disrupts and reshapes the retail sector. Given the facts that retail accounts for a significant fraction of GDP and employment ${ }^{3}$ and retail is one of the first sectors that embrace the Internet, the evolution of online and offline retail sheds important lights on the digitalization of the overall economy.

This paper examines a particular form of online-offline interaction, namely a manufacturer with an established offline brand may open a flagship store on an e-commerce platform. This partnership brings interesting economics for the brand, the platform, and other users on the platform.

From the brand's perspective, flagship entry allows it to access consumers that shop in a popular virtual mall. Although these consumers can access the brand via physical stores or the brand's own website, many of them prefer an online marketplace because it is easier to search across a wide range of brands in one portal. However, flagship entry is not the only way to access these consumers. The brand can designate agents to sell at the same virtual mall. The brand's products may also be sold in the virtual mall by other sellers. Opening a flagship store can enhance brand awareness but the flagship store competes headto-head with other same-brand sellers, and has a potential to cannibalize their sales. The cannibalization could be beneficial to the brand if it diverts traffic from other sellers, but

\footnotetext{
${ }^{1}$ Some brands such as Toys 'R' Us and Nike had first partnered with Amazon and then severed the ties. See more details at Fortune 11/13/2019 https://fortune.com/2019/11/ 13/nike-ends-amazon-deal/\# : : text=Nike\%20Inc. \%20is\%20breaking\%20up, program\%20that\% 20began\%20in\%202017 and Seattle Times 06/13/2009 https://www.seattletimes.com/business/ amazon-settles-long-standing-legal-dispute-with-toys-r-us/.

${ }^{2}$ See Axios.com (12/6/2017) "Luxury Brands win rights to stop sales on Amazon in Europe", at https:// www . axios.com/luxury-brands-win-right-to-stop-sales-on-amazon-in-europe-2515350463.html, accessed on October 5, 2020.

${ }^{3}$ For example, according to the National Retail Federation, in 2018 there were nearly 4.2 million retail establishments in the US, accounting for $11.6 \%$ of all business establishments, $16 \%$ of jobs, $8.3 \%$ of labor inome, and $7.7 \%$ of GDP in the US. Source: "The Economic Impact of the US Retail Industry", by PWC and National Retail Federation, May 2020, accessed at https://cdn.nrf.com/sites/default/files/2020-06/RS118304\%20NRF\%20Retail\%20Impact\%20Report\%20.pdf on April 29, 2022.
} 
ambivalent if it shifts the brand's revenue from wholesale orders to the flagship store. Under some conditions, the brand may even want to restrict other sellers in the virtual mall, or require the platform to chase out certain sellers before it opens a flagship store there. ${ }^{4}$

Economic incentives are quite different for the platform. A flagship store can bring in new consumers, especially if the brand is popular and consumers tend to avoid the brand's product on the platform due to quality concerns. However, cannibalization can be non-trivial if the brand's products already have large sales by other sellers, which generates commissions and fee revenue for the platform. Because of these trade offs, it is unclear whether the platform should attract flagship stores with subsidy, or resist the brand's request to limit certain sellers on the platform. Apparently, consumers that prefer lower price, higher quality assurance and wider variety may not have their interests fully aligned with those of the platform, the brand, and other sellers.

To investigate economic incentives of all parties, we study a large e-commerce platform that hosts three types of stores. The first one is a flagship store operated by a brand manufacturer, with an exclusive focus on the brand's products; the second one is business-toconsumer ("B2C") stores operated by registered companies but not the brand itself; and the third one is consumer-to-consumer stores ("C2C") operated by individual sellers. Both B2C and $\mathrm{C} 2 \mathrm{C}$ stores may sell multiple brands at the same time. Our analysis focuses on a leading product category within cosmetics, which includes many brands with differential prominence among consumers (referred to as "Category A" thereafter). The same methodology can be easily extended to other categories.

We adopt the standard empirical framework of industrial organization (IO) to analyze demand, supply and market outcomes. In particular, our demand estimation is built upon the standard discrete choice model with aggregate market share data (i.e., the BLP model following Berry et al. (1995)). In our supply model, we allow the flagship pricing decision to incorporate its competitive spillover on other sellers, similar to how Sudhir (2001a,b) modeled multiple retail channels in automobile and grocery markets. To the extent that sales from other sellers could generate wholesale profits for the brand, the spillover may motivate the brand to soften its price competition with these sellers. Conversely, the brand may want to punish other sellers if these sellers sell inferior products and undermine the brand's reputation. Also, within the same brand, we can back out different stores' marginal cost separately.

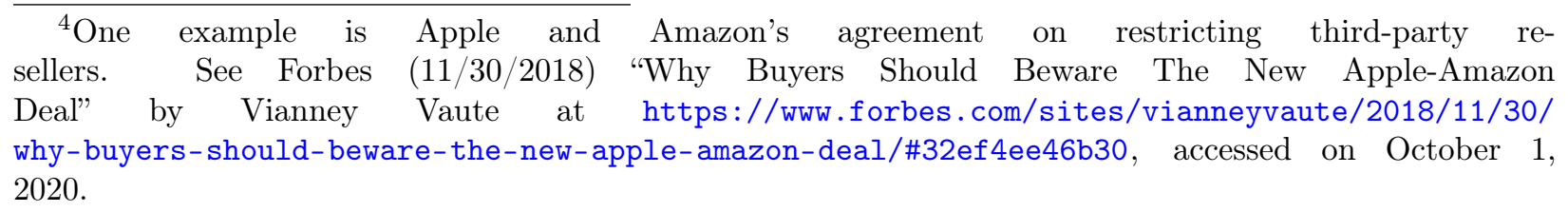


Based on demand and supply estimates, we conduct a series of counterfactual simulations. The baseline case is opening a new flagship store for the brands that have not done so. This counterfactual suggests which flagship store the platform should attract or avoid. We then extend the baseline simulation to the cases where a flagship entry comes with restrictions on other sellers of the same brand, such as eliminating business sellers of the same brand, eliminating individual sellers, or keeping only the top $10 \%$ of $\mathrm{B} 2 \mathrm{C}$ and $\mathrm{C} 2 \mathrm{C}$ sellers.

We find flagship entry is beneficial to the platform and the entering flagship store, but hurts $\mathrm{B} 2 \mathrm{C}$ and $\mathrm{C} 2 \mathrm{C}$ sellers of the same brand. This is intuitive because the flagship store expands consumer choice set, intensifies price competition, and cannibalizes other sellers of the same brand. On average, the effect on consumer welfare is positive if the flagship entry is from a non-prominent brand, but negative if the flagship entry is from a prominent brand. This happens because the two types of flagship entry have different spillovers on other brands. Upon a non-prominent flagship entry, consumers increase their willingness to pay for all types of sellers of other brands, which boosts consumer surplus. In contrast, when the flagship entry is from a prominent brand, consumers tend to lower their willingness to pay for $\mathrm{C} 2 \mathrm{C}$ sellers of other brands, likely because the entry has raised quality concern for $\mathrm{C} 2 \mathrm{C}$ sellers in general. If this change reflects a correction of consumer perception, the reduced consumer surplus could be beneficial to consumers as well. When we allow flagship entry to be accompanied by constraints on other same-brand sellers, simulation suggests the reduced competition would benefit the flagship store but hurt consumers, regardless whether the entry brand is prominent or non-prominent.

Besides the papers mentioned above, our work relates to several strands of empirical IO literature. Our demand model is similar to Grennan (2013), Foncel and Ivaldi (2005) and Berry and Jia (2010), and our supply side model is closely related to the literature on examining firm conduct and market structure, see Nevo (2001), Ciliberto and Williams (2014), among others. To the extent that flagship entry increases product variety for consumers on the platform, it is similar to the variety effects demonstrated in the introduction of minivans (Petrin (2002)), radio stations (Berry and Waldfogel (1999)) and commercial trucks (Wollmann (2018)). Other related studies on entry include Jia (2008), Seim and Waldfogel (2013), Economides et al. (2008), Fan and Yang (2020) and Houde et al. (2017), among others. Our paper contributes to the literature by offering new evidence on the strategic interactions between incumbents and entrants in a large-scale online marketplace.

The brand-retailer interaction entailed by flagship entry is akin to the introduction of store brands in traditional retail, although sellers on an online platform sell directly to end consumers while branded manufacturers interact with retailers via wholesale contracts. As shown by Chintagunta et al. (2002) and Pauwels and Srinivasan (2004), store brand en- 
try tends to benefit the retailer and the consumers, leave premium-brand manufacturers unaffected, but hurt second-tier brand manufacturers. These effects occur as store brands enlarge product assortment, intensify competition in price and promotional activities, enhance the retailer's bargaining ability vis-a-vis national brands, and at the same time have little effect expanding category sales or retail traffic. In comparison, flagship entry in online marketplaces does not only enhance product variety and price competition, but also change consumer perception of other sellers on the platform. These spillovers could affect the overall customer base and total sales on the platform.

The extra market expansion effect of flagship entry is related to the classical fight between brand manufacturers and third-party resellers. Brand manufacturers have strong qualityassurance or brand-protection incentives to distinguish from third-party resellers, but consumers may find third-party resellers appealing due to lower price and status consumption (Grossman and Shapiro (1988), Qian (2008)). Flagship entry can convince consumers that products directly sold by brand manufacturers are now available on the platform.

More broadly, flagship entry enriches the set of strategic arrangements between branded manufacturers and retail channels. Without online marketplaces, branded manufacturers could sell wholesale to retail stores, designate resellers, open their own outlets offline, and/or sell online via catalog or website. Flagship entry is a new form of retail channel that could facilitate a win-win-win scenario: consumers benefit from larger seller-brand selection, lower price, and higher (perceived) quality; the brand benefits from a wider reach of consumers and a better ability to cannibalize other sellers; and the platform benefits from a bigger customer base and their higher willingness to pay. As shown in our simulations, benefits to consumers are the greatest if flagship entry is accompanied by no restriction on other sellers of the same-brand. However, the entry brand may prefer some restrictions on these sellers, because their profits rise with less competition within the same brand. The platform's interest lies somewhere in between, as its total GMV (gross merchandise value) depends on both price and quantity.

In the rest of the paper, Section 2 describes the background and the data. Section 3 presents a structural model of demand and discusses the demand estimates. Section 4 models the supply side and presents supply estimates. Section 5 conducts counterfactual simulations. Section 6 concludes. 


\section{Background and Data Description}

\subsection{Background on Online Flagship Stores}

Flagship store of a brand is a special distributor owned by the brand itself. The flagship store usually has certain competitive advantages over other third-party retailers, e.g., it can provide better product quality control and after-sales services. Appendix Figures 14 and 15 present two screenshots on how a flagship store looks like on a popular online marketplace (not necessarily the platform we study), and how a comparison shopping page of the marketplace distinguishes flagship from other types of stores. In both screenshots, the platform ensures consumers that the flagship store is authentic and official, is operated by the brand directly, and sells the brand's products exclusively.

In recent years, flagship stores, as a new form of collaboration between platform and brands, have been remarkably successful. Figure 1 shows the growth of GMV of three different channels - flagship store, non-flagship B2C sellers (we will omit "non-flagship" for the sake of brevity thereafter), and $\mathrm{C} 2 \mathrm{C}$ sellers - in the cosmetics category of our study platform (our later analysis will focus on part of this broad category). To protect the business secrets of the platform, GMV on the vertical axis is normalized. Compared to C2C and $\mathrm{B} 2 \mathrm{C}$ sellers, we can see that flagship stores have become a major type of players on the platform's marketplaces.

Figure 2 shows the total number of sellers by channel (normalized, in log-scales). There are fewer flagship stores than B2C sellers; and the number of flagship stores is only a small fraction of that of $\mathrm{C} 2 \mathrm{C}$ sellers. Since the total GMV of flagship stores is comparable with the sum of $\mathrm{C} 2 \mathrm{C}$ and $\mathrm{B} 2 \mathrm{C}$ sellers, on average a flagship store generates much more GMV than

a single $\mathrm{C} 2 \mathrm{C}$ and $\mathrm{B} 2 \mathrm{C}$ seller, which suggests that consumer preference for flagship stores is rather strong.

As shown in Figure 2, the number of flagship stores has been steadily increasing over the last few years. This could be a result of brands reaching out to the platform or the platform reaching out to certain brands for strategic partnership. There is no doubt that the timing of each flagship entry may depend on brand attributes and business strategy, which we do not fully observe as researchers. However, the platform often negotiates with multiple brands at the same time (separately), and how each contract process plays out is subject to many idiosyncratic factors. To address the potential endogeneity of flagship entry, our demand estimation controls for a complete set of brand-seller-year fixed effects, which should absorb each brand's yearly strategy in business development. With this control, we assume the exact timing at which the flagship entry occurred within the year is exogenous. As detailed later on, we also perform statistical tests based on our demand and supply estimates. These 
estimates indicate that the specific timing of flagship entry has little to do with the perceived quality of the brand or the realized profits of the brand's flagship store.

The platform offers a menu of seller services on shipping \& handling, advertising, promotional programs, etc. Every seller can choose what services to use based on their own customer base, inventory, business development plan, and budget. Different sellers may end up choosing different services - for example, flagship stores and B2C sellers are much more likely than $\mathrm{C} 2 \mathrm{C}$ sellers to participate in the annual sales event (hosted by the platform each year in November), because C2C sellers are much more limited in inventory and cannot handle large demand shifts as quickly. For the same reason, not all B2C sellers participate in the annual sales event every year, but those who participate often offer significant discount and handle a unusually large quantity of sales. This explains why, in Figure 1, the total flagship GMV have a much sharper up-shot spike than B2C and C2C GMV in the calendar month corresponding to the platform's annual shopping festival. In addition, C2C GMV has a deeper dip around a major lunar calendar holiday for the home country of the platform each year, because most $\mathrm{C} 2 \mathrm{C}$ sellers are individuals and do not have extra personnel to work overtime during the festival.

Overall, the active entry and business success of flagship stores raise a natural question: what are the impacts of flagship entry on consumers, other sellers and the platform? This is the focus of our analysis.

\subsection{Data Source and Sample Construction}

Our analysis is based on a representative sample of sellers ${ }^{5}$ in a leading category of cosmetics (Category A) on $\mathrm{B} 2 \mathrm{C}$ and $\mathrm{C} 2 \mathrm{C}$ markets. In particular, the data contain monthly quantity and price (as well as some other variables) at seller-item level for 54 consecutive months between 2010 and 2020. We aggregate the raw item-seller-month data into brand-sellermonth because there is no universal identifier of an item in the data, ${ }^{6}$ Brands included in our sample account for about $90 \%$ of the total GMV in Category A.

For a brand-seller-month, price is constructed as the ratio between total sales and total quantity, while sales and quantity are a simple aggregation from the item-level data within the combination. By this definition, price is a quantity-weighted average of transaction price. Because our data is monthly, we observe price variations across brand-sellers and across months, but not within a brand-seller-month. We also observe seller characteristics

\footnotetext{
${ }^{5}$ The sampling is in compliance with the data use agreement between the platform and the sellers on its marketplaces. Also, the data are de-identified and thus do not contain any information that reveals individual identity.

${ }^{6}$ Two identical products could have two different product codes at two different stores, while a brand can be identified across sellers.
} 
such as rating, number of listing, etc, as well as an indicator for whether a brand is prominent brand. We were told that brand prominence is one of the most important brand attributes, and the distinction is most robust in a binary indicator of prominent versus non-prominent as defined by the platform.

Figure 3 plots the trends of price indices of the three channels in the sample we constructed for Category A. We can see that flagship stores' price is on average higher than other B2C stores, which in turn is higher than C2C stores. Standard oligopolistic pricing theory tells us that the price difference among the three channels are driven by markup (as a measure of market power) and marginal cost. Distinguishing these two factors is an important part of our empirical analysis using a structural model.

Figure 4 shows the quantities sold by the three channels. Although the number of flagship stores has increased over time and flagship stores are more likely to participate in the annual sales event, the overall growth and spikes in the quantity sales of flagship stores do not associate with decreases in $\mathrm{B} 2 \mathrm{C}$ and $\mathrm{C} 2 \mathrm{C}$ stores, at least not in a similar magnitude. This suggests that flagship entry has a substantial market expansion effect, i.e., attracting consumer demand outside those that have already purchased in Category A on the platform's marketplaces.

Figure 5 examines the percent of flagship store among prominent and non-prominent brands, respectively. The fraction of prominent brands that own a flagship store on B2C Market increases from $20 \%$ to almost $80 \%$ during our sample period, while for non-prominent brands, the fraction is growing at a slower rate. The distinct trends of growth for prominent and non-prominent brands suggest that their incentives of opening flagship stores may be different. This motivates us to examine prominent and non-prominent brands separately in the structural model.

Table 1 highlights more differences between prominent and non-prominent brands as of the last month in our sample. The first three columns - on the number of unique brands, unique sellers, and unique brand-sellers - are normalized by the count of non-prominent flagship stores $(N)$. For example, if $N=100$ (hypothetically), it means 100 non-prominent brands had flagship stores as of last month in our sample, but at the same time 5,326 sellers sold 154 non-prominent brands on C2C Market and 1,290 sellers sold 56 non-prominent brands on B2C Market. These numbers are different from 100 because brands could be sold without a flagship store and not all brands with a flagship store are carried by $\mathrm{C} 2 \mathrm{C}$ or $\mathrm{B} 2 \mathrm{C}$ sellers. In combination, the first three columns suggest that on average, a $\mathrm{C} 2 \mathrm{C}$ or $\mathrm{B} 2 \mathrm{C}$ seller has sales on fewer than 2 non-prominent brands, while a non-prominent brand may be sold by $69 \mathrm{C} 2 \mathrm{C}$ sellers or $3.7 \mathrm{~B} 2 \mathrm{C}$ sellers. In comparison, if $N=100$, only 10 prominent brands had a flagship store, 1,896 sellers sell 15 prominent brands on C2C Market, and 39 sellers 
sell 8 prominent brands on B2C Market. Despite a lower count in prominent brands, the average number of sellers per prominent brand is larger than that of non-prominent brands, suggesting more fierce competition in prominent brands.

Price-wise, flagship stores charge a higher price than B2C sellers, who in turn price higher than $\mathrm{C} 2 \mathrm{C}$ sellers. This pattern is more apparent for prominent brands, probably because the flagship price of prominent brands more than doubles that of non-prominent brands. The price gap between flagship store and other sellers is also greater for prominent brands, suggesting that consumers may put a substantial quality premium on the flagship when the brand is more prominent. At the brand-seller-month level, total quantity sold in a flagship store is almost an order of magnitude higher than an average B2C seller, and two orders of magnitude higher than an average $\mathrm{C} 2 \mathrm{C}$ seller. However, there are many more $\mathrm{C} 2 \mathrm{C}$ sellers than $\mathrm{B} 2 \mathrm{C}$ sellers, so the aggregate share of quantity sold is larger for flagship and $\mathrm{C} 2 \mathrm{C}$ than for the $\mathrm{B} 2 \mathrm{C}$ channel.

\subsection{Reduced-Form Analysis}

Before setting up a formal structural model, we conduct a reduced-form analysis on how the number of flagship stores (for own brand and competing brands) affects the prices and quantities of products in different channels and for different types of brands (prominent or non-prominent). By definition, the analysis sample includes the sellers of the brands with and without flagship entry during our sample period. These sellers could be flagship, B2C, or $\mathrm{C} 2 \mathrm{C}$. The unit of observation is brand-seller-month. The key right hand variables are three flagship indicators: an indicator of whether the seller's own brand has a flagship store on the B2C Market; the number of flagship stores by other prominent brands; and the number of flagship stores by other non-prominent brands. The coefficient on the indicator for the presence of flagship store can be interpreted as a difference-in-differences estimator of the within-brand effect (on $\mathrm{B} 2 \mathrm{C} / \mathrm{C} 2 \mathrm{C}$ sellers) of flagship entry, while not explicitly modeling the positive or negative spillovers between flagship, B2C and $\mathrm{C} 2 \mathrm{C}$ sellers due to competition. The results are shown in Table 2 .

In panel I, we regress product (i.e., brand-seller-month) level price (log scale) on the three flagship indicators, while controlling for brand-seller fixed effects and year-quarter fixed effects. This regression is run by brand type (prominent or non-prominent) and sales channel (flagship, B2C, and $\mathrm{C} 2 \mathrm{C}$ ) separately. As flagship stores from other brands enter the market, the prices of $\mathrm{C} 2 \mathrm{C}$ sellers increase slightly while those of $\mathrm{B} 2 \mathrm{C}$ and flagship stores decrease. Overall, these cross-brand price effects are much weaker than the within-brand effects, suggesting greater differentiation across brands than within-brand. 
We conduct the same analysis for quantity in panel II of Table 2. Since this analysis focuses on quantity and the distribution of quantity varies hugely across sellers, we weight the quantity regression by GMV (at the brand-seller-month level). We find the flagship entry of a prominent brand is associated with an increase in the sales quantity of other brands' $\mathrm{B} 2 \mathrm{C}$ and flagship stores, but a decrease in the quantity of their $\mathrm{C} 2 \mathrm{C}$ sellers (the magnitude is sizeable at around 1-2\% for one flagship entry). Also, across all channels and brand types, the brand-seller level quantity is positively correlated to the flagship entry of a nonprominent brand, though the effect is much smaller than that of a prominent brand. These results, driven by the mix of market expansion and business stealing/cannibalization effects, suggest that flagship entries can attract new consumers into the market and/or increase their willingness-to-pay for other brands.

Panel III of Table 2 summarizes effects of the number of flagship stores on the platform's total GMV across different seller groups. To perform the analysis, we aggregate GMV by each seller group in each year-month, resulting in total 54 observations. Results suggest that all types of stores benefit substantially from an increasing number of flagship stores of non-prominent brands, however, the effects of prominent flagship entry are not significant. This suggests that overall the market expansion effect is more related to non-prominent flagship entries and might prevail over the cannibalization (within-brand) and businessstealing (across-brand) effects on the market.

In short, the reduced-form analyses suggest that flagship entry has notable impacts on own and other brands. However, these reduced-form regressions are conducted for each brand type and channel separately, ignoring the fact that products of different brand types and different channels are substitutes, and their competition can be reshaped by flagship entry. Moreover, it does not fully address the potential endogeneity of flagship entry, though the control of brand-seller fixed effects should alleviate the concern to some extent. Understanding the full picture of competition would require estimating a structural model of the whole market. This is the main task of the following sections.

\section{Demand Estimation}

In this section, we set up a model of consumer demand for Category A and estimate it using brand-seller-month level sales data. In particular, we use a multi-level nested-logit model, which resembles those in Verboven (1996); Foncel and Ivaldi (2005); Grennan (2013) and falls into the general BLP framework (see Berry (1994); Berry et al. (1995)), with some specifications tailored to our application. 


\subsection{Basic Setup}

There are $M_{t}$ potential consumers (a.k.a. market size) in month $t$, with $M_{t}$ being defined by the number of monthly "active users" of the platform's marketplaces (users who bought at least one item from the marketplaces in the month).

For each month $t$, each consumer $i$ chooses either product $j=1, \ldots, J_{t}$, defined as a brand-seller-year combination listed in Category A, or the outside option of not buying any products in Category A on the platform (labeled as 0).

As illustrated in Figure 6, consumer preference is represented by a multi-level nested logit demand model: each consumer first chooses a brand, then a channel (Flagship, B2C or $\mathrm{C} 2 \mathrm{C}$ ), and finally a seller. The outside option is assumed to be a singleton branch at the first tier. The Flagship channel at the second level does not have a successor at the third level because each brand can have no more than one flagship store for a given product category. As a robustness check, we have tried alternative specifications, e.g., switching the order of brand and channel to the "channel-then-brand-then-seller" structure, and adding additional layer(s) of nests. As shown in Appendix A.1, results suggest that these alternative nesting structures are likely mis-specified.

Formally, the utility to consumer $i$ of buying product $j$ in market $t$ is

$$
u_{i j t}=X_{j t}^{\prime} \beta+\xi_{j t}+\nu_{i j t} .
$$

Here, $X_{j t}$ is a vector of observed product characteristics (including price), $\beta$ is a vector of coefficients to be estimated, $\xi_{j t}$ is an unobserved product characteristic, $\nu_{i j t}$ is a preference shock that follows the multi-level nested logit specification, i.e.,

$$
\nu_{i j t}=\epsilon_{i, b, t}+\left(1-\lambda_{b}\right) \epsilon_{i, b c, t}+\left(1-\lambda_{b c}\right) \epsilon_{i j t},
$$

where $\epsilon_{i, b, t}$ is a random variable common to all the products of brand $b, \epsilon_{i, b c, t}$ is a random variable common to all the products in brand-channel group $b c$ (assuming $j$ is in group $b c$ and $b), 0 \leq \lambda_{b} \leq \lambda_{b c} \leq 1$ are the nesting parameters capturing within-group correlations among the same brand and the same brand-channel, respectively, and $\epsilon_{i j t}$ is the standard type-I extreme value error term (contains scale normalization of the model). We normalize the level of the model by setting the characteristics $(X$ and $\xi)$ of the outside good to 0 .

Each consumer chooses the product that maximizes her utility and the aggregation of all consumer choices yields market shares. Given the nested-logit specification, the relative market share of product $j$ with respective to the outside option in market $t$ can be written 
in logarithmic form as (see, among others, Verboven (1996) for a derivation)

$$
\log \left(\frac{s_{j t}}{s_{0 t}}\right)=X_{j t}^{\prime} \beta+\lambda_{b} \log \left(s_{c \mid b, t}\right)+\lambda_{b c} \log \left(s_{j \mid b c, t}\right)+\xi_{j t}, \forall j, t
$$

where $s_{j t}$ is the market share of product $j$ in market $t, s_{c \mid b, t}$ is the conditional share of $c$ within brand $b$, and $s_{j \mid b c, t}$ is the conditional share of $j$ within brand $b$ and channel $c$.

The market share of product $j>0$ in market $t$ is defined as $s_{j t}=\frac{q_{j t}}{M_{t}}$, where $q_{j t}$ refers to the quantity of sales; the outside share $s_{0 t}$ equals to $1-\sum_{j=1}^{J_{t}} s_{j t}$. All the other group shares can be calculated based on these product shares.

The nested-logit structure is in general more restrictive than a full-blown mixed-logit specification in terms of capturing consumer taste heterogeneity. However, it has the key advantage of yielding a close-form inverse demand function and hence the linear estimation equation (1). As we shall see below, the linear form enables us to leverage panel data estimation techniques to control for product fixed effects and address the endogeneity problem caused by price as well as the within-group shares. Also, it allows us to easily incorporate heterogeneous parameters among different channels and types of brands (prominent vs non-prominent brands), which in turn implies a rather flexible substitution pattern among products beyond the simple nested logit. Section 3.4 describes a series of robustness checks we have done on alternative demand specifications, including one with a random coefficient on price.

\subsection{Identification Assumptions and Estimation}

To estimate the demand parameters in equation (1), we need to impose statistical assumptions on the error term $\xi_{j t}$. Specifically, exploiting the panel structure of our data, we assume $\xi_{j t}$ follows an auto-regressive process of order $K(\operatorname{AR}(K))$ :

$$
\xi_{j t}=\sum_{k=1}^{K} \rho_{k} \xi_{j, t-k}+\tilde{\xi}_{j t}
$$

which implies the following equation,

$$
\begin{aligned}
\log \left(\frac{s_{j t}}{s_{0 t}}\right) & =X_{j t} \beta+\lambda_{b} \log \left(s_{c \mid b, t}\right)+\lambda_{c} \log \left(s_{j \mid b c, t}\right) \\
& +\sum_{k=1}^{K} \rho_{k}\left[\log \left(\frac{s_{j, t-k}}{s_{0, t-k}}\right)-X_{j, t-k} \beta-\lambda_{b} \log \left(s_{c \mid b, t-k}\right)-\lambda_{c} \log \left(s_{j \mid b c, t-k}\right)\right] \\
& +\tilde{\xi}_{j t} .
\end{aligned}
$$


Then, using Arellano and Bond (1991)'s approach, we estimate (3) based on the following moment conditions:

$$
E\left[\Delta \tilde{\xi}_{j t} Z_{j t}\right]=0, t=K+2, \ldots, T
$$

where $\Delta \tilde{\xi}_{j t}=\tilde{\xi}_{j t}-\tilde{\xi}_{j t-1}$ and $Z_{j t}$ is a set of instrumental variables, including exogenous variables and lagged (with lag order $K+1$ periods and more) endogenous variables (i.e., market shares and price).

We allow auto-correlation in the error term $\xi_{j, t}$ because the monthly time series of a product's market share tends to exhibit strong persistence even after controlling a rich set of covariates, including market-level year-month fixed effects. Empirically, we find the AR(K) process to be statistically significant until $K=3$ and the Arellano-Bond test for autocorrelation favors $K=3$ (over $K=1,2$ ), so we report our demand estimates under $\mathrm{AR}(3)$.

Once we control for product fixed effects and $\operatorname{AR}(3)$ of $\xi_{j, t}$, seller attributes (such as seller ratings, number of listings) are either dropped due to collinearity or have statistically zero coefficient. So we do not include them in the reported demand estimation.

Several remarks on identification are in order. The first issue is that flagship entry could be endogenous. Recall that a product $j$ is defined as a brand-seller-year combination and $t$ labels year-month. This allows us to control for brand-seller-year fixed effects in $X_{j t} \beta$, which addresses the potential endogeneity of flagship entry driven by a brand's year-by-year variation in business strategy. We can also correlate the timing of flagship entry with the estimated brand-flagship-year fixed effects and the simulated flagship store profit post entry. Should high-quality or high-profit brands be more likely to open the flagship store early, these correlations should be rather positive. As shown later, both correlations turn out to be very weak, providing little support for the concern of selective flagship entry.

As demonstrated in Berry (1994), price and group market shares are endogenous and need instruments. With product fixed effects and lagged endogeneous variables, equation (3) is effectively a dynamic panel data model, which allows us to use predetermined variables to form orthogonality conditions, like (4). In fact, this strategy is commonly used in demand and production function estimation literature, see, e.g., Sweeting (2013), Doraszelski et al. (2018), among others.

In particular, since our panel data structure has a small $T$ (12 months) and large $J$ (hundreds of thousands of products), Arellano and Bond (1991)'s method becomes a natural option for estimating (3). The moment conditions (4) are constructed based on Arellano and Bond (1991): the difference $\Delta \tilde{\xi}_{j t}$ is taken to remove the product fixed effects and then assumed to be uncorrelated with $Z_{j t}$, which includes previous endogenous variables as in- 
struments to address the endogeneity problem. These IVs are different from the standard BLP-type IVs that are based on the assumed exogenous product characteristics space. We do not use the BLP-type IVs here because they are likely to be endogenous due to the rapidly changing market structure (very frequent entry and exit) and actually yield unreasonable estimation results, e.g., positive price coefficients, nesting parameters greater than 1 .

Another potential issue we encounter in the estimation is that there is a non-negligible fraction of zero market shares in the data. According to a recent study by Gandhi et al. (2019), ignoring the zero shares introduces a selection problem that could generate serious bias to the estimation of parameters such as price coefficient. To address this problem, we apply Gandhi et al. (2019)'s main idea of estimating the model based on a set of "popular products" that are unlikely to have zero sales.

In particular, by exploiting the panel data structure, we define popular products to be those that never experience zero sales during their life cycle on $\mathrm{C} 2 \mathrm{C} / \mathrm{B} 2 \mathrm{C}$ within one year (recall that a product is defined as a brand-seller-year combination). Then our estimation is based on this selected sample of popular products. We acknowledge that this estimation strategy involves efficiency loss because we are not using the full sample, however, given our experiences with the data and estimation, it seems that the bias caused by zero shares is a more important issue to address (see Section 3.4 for a robustness check on this issue).

\subsection{Estimation Results}

The variables included in $X_{j t}$ are price (log scale), an indicator for the existence of a flagship store of product $j$ 's own brand, year-month dummy, as well as product dummy (removed by the differencing procedure in (4)). We do not include the total number of flagship stores on the platform because they are absorbed by year-month fixed effects. We include a dummy of own brand flagship because the mere existence of flagship could affect consumer perception of the same-brand products sold by $\mathrm{C} 2 \mathrm{C}$ or B2C sellers.

To obtain a flexible substitution pattern among products, we allow the parameters, especially price coefficient and the nesting parameters that jointly determine price elasticities in the current nested logit model, to vary by product groups defined by channel and brand type (i.e. prominent or not). ${ }^{7}$

Table 3 reports the demand estimation results. First, we can see that the (log) price coefficients, measuring price sensitivity, are smaller for prominent brands than for non-prominent ones in absolute value for each channel. Also, flagship store faces greater price sensitivity

\footnotetext{
${ }^{7}$ This is more flexible than the classical nested logit model, as that model is equivalent to assuming the nesting parameters to be the same for all channels and all types of brand. Appendix Table 15 reports results from this restricted model, and the implied price elasticities are similar to our main results.
} 
than $\mathrm{C} 2 \mathrm{C}$ and $\mathrm{B} 2 \mathrm{C}$ sellers. In all the cases, the estimated nesting parameters satisfy the theoretical restriction $0 \leq \lambda_{b} \leq \lambda_{b c} \leq 1$, which guarantees that the model is consistent with utility maximization behavior. Most of the estimated nesting parameters are rather large, suggesting that the nests are properly defined, except $\lambda_{b}$ for $\mathrm{C} 2 \mathrm{C}$ stores, which is around .10 meaning the within-brand substitution between $\mathrm{C} 2 \mathrm{C}$ and other channels is quite weak. This is sensible because $\mathrm{C} 2 \mathrm{C}$ sellers are more idiosyncratic than flagship and B2C stores and tend to lay more emphasis on personalized services.

Regarding the effect of flagship entry, we can see that the demand of a brand sold on $\mathrm{C} 2 \mathrm{C}$ Market is negatively affected by the entry of the brand's own flagship store, while it is the opposite for B2C. This is intuitive, as flagship entry may remind consumers that B2C sellers are registered companies and likely have more reliable product source and product services than individual sellers on $\mathrm{C} 2 \mathrm{C}$ Market. However, the positive coefficient on the own-brand flagship dummy does not mean B2C sellers would enjoy more sales post its own-brand's flagship entry. This is because consumers often view flagship store of the same brand as of a much higher quality (as reflected in the estimated product fixed effects where a product is defined by brand-seller-year), and consumer choice depends on the relative comparison across products.

Given the estimates reported in Table 3, we obtain a demand "residual":

$$
\begin{aligned}
\hat{\Delta}_{j t} & \equiv \log \left(\frac{s_{j t}}{s_{0 t}}\right)-\hat{\beta}_{\text {price }} \log \left(\text { Price }_{j t}\right)-\hat{\lambda}_{b} \log \left(s_{c \mid b, t}\right)-\hat{\lambda}_{b c} \log \left(s_{j \mid b c, t}\right) \\
& -\hat{\beta}_{\mathrm{FS} \_ \text {entry }} 1(j \text { 's Flagship Store Exists in } t) .
\end{aligned}
$$

By definition, this "residual" contains product fixed effects, year-month fixed effects, and unobserved product attributes $\xi_{j t}$. If flagship entries affect the overall attractiveness of the platform, such market-wide spillovers would be absorbed in year-month fixed effects. We need to further decompose year-month fixed effects, because for our later counterfactual experiments where we simulate the effects of a hypothetical flagship entry, we need to impute how the entering flagship store affects other brands' $\hat{\Delta}$ 's. To facilitate this exercise, we regress $\hat{\Delta}$ on two predictors, the number of prominent flagship stores and the number of non-prominent ones, while controlling product fixed effects and month fixed effects (January to December, not year-month) for each of the product groups defined by channel and brand type. The estimated coefficients on the two predictors and the mean product fixed effects (for each) are reported in Table 4.

From Table 4, we can see that the entry of a prominent flagship store reduces C2C sellers' $\hat{\Delta}$ but lifts B2C sellers' $\hat{\Delta}$. In comparison, the entry of a non-prominent flagship store raises $\hat{\Delta}$ for all types of sellers in the market. This suggests that the market expansion effect 
on other brands is more likely driven by non-prominent brands than by prominent brands. In fact, because $\mathrm{C} 2 \mathrm{C}$ sellers account for more sales in total than $\mathrm{B} 2 \mathrm{C}$ sellers, a prominent flagship entry could even shrink the market for some other brands, although the flagship's own product fixed effect, if very high, could attract many buyers to the platform for that flagship store.

Figure 7 plots the histogram of the estimated product fixed effects for prominent and non-prominent brands separately. Within non-prominent brands, the distribution of product fixed effects is comparable between flagship, B2C and $\mathrm{C} 2 \mathrm{C}$, except that the flagship distribution has a slightly higher mean and a wider distribution. In comparison, for prominent brands, the average flagship fixed effect is much greater than that of $\mathrm{B} 2 \mathrm{C}$ or $\mathrm{C} 2 \mathrm{C}$, suggesting that on average consumers place a much higher quality premium on the flagship store of prominent brands, and this premium varies greatly by brand. These results hint that when a prominent brand opens a flagship store, it can have substantial cannibalization effects on other sellers of the same brand. Finally, for both prominent and non-prominent brands, the mean of the estimated B2C fixed effects is lower than that of $\mathrm{C} 2 \mathrm{C}$ fixed effects, because not all brands have $\mathrm{B} 2 \mathrm{C}$ sellers, and $\mathrm{C} 2 \mathrm{C}$ sellers are more likely to sell something under an attractive brand.

Next, using the parameter estimates in Table 3, we compute the implied price elasticities and summarize them in Table 5. The table only shows the price elasticities for the last month in our data, as results for other months are very similar.

One interesting observation about own price elasticities is that $\mathrm{C} 2 \mathrm{C}$ sellers face much more inelastic demand (it is even inelastic for prominent brands) than B2C and flagship stores. This result is somewhat counter-intuitive from the traditional market structure point of view because $\mathrm{C} 2 \mathrm{C}$ Market seems more competitive than $\mathrm{B} 2 \mathrm{C}$ (recall that Flagship stores are on the B2C Market): the number of sellers on C2C Market is greater in a factor of 20 than that on B2C Market; and the entry cost (cost of opening an online store) is much lower on the $\mathrm{C} 2 \mathrm{C}$ Market than the B2C Market.

We can think of at least three explanations: First, products sold on the B2C Market are typically branded and rather homogeneous (within a brand) across different sellers in the marketplaces. It is also easily comparable with other e-commerce platforms and even offline channels. Given the head-to-head competition between different outlets (including e-commerce platforms and brick-and-mortar stores), consumers can easily substitute to different sellers both within the B2C Market and across different outlets when buying a branded or standardized product. ${ }^{8}$ In contrast, products sold on $\mathrm{C} 2 \mathrm{C}$ Market are not standardized

\footnotetext{
${ }^{8}$ Intensified comparison shopping across different retail outlets may also explain why the price elasticity of prominent flagship store is higher than that of non-prominent flagship store, although consumers associate
} 
and sellers have more freedom to differentiate their products (e.g., packaging, promotion, bundling), services (e.g., shipping options) and themselves (e.g., rating scores, customer loyalty), which effectively soften the price competition on the platform. ${ }^{9}$ Related discussions can be found in Dinerstein et al. (2018), among others.

Second, B2C and $\mathrm{C} 2 \mathrm{C}$ sellers may face a tighter quantity constraint on a particular product than the same brand's flagship store. When they lower the product's price, they are more likely to find the constraint binding, which looks like less quantity response to a price change in the raw data. It is also possible that $\mathrm{B} 2 \mathrm{C}$ and $\mathrm{C} 2 \mathrm{C}$ sellers are more likely to use products that are popular but of limited supply as a loss-leader. In that case, lower price on those loss-leaders do not correspond to a large increase in their quantity sold. ${ }^{10}$ Thirdly, most C2C sellers rank far from top in search results, because they are small, idiosyncratic in service quality, and likely to face inventory constraint. As a result, discount by these opaque sellers is also less visible, which implies less response from consumers.

As a sanity check, we plot the estimated own elasticities along with actual quantity and price data in Figure 8 and 9 for prominent and non-prominent brands, respectively. In Figure 8, a dark circle dot represents the actual price and quantity (both in log-scale and then normalized by the range of y-axis) of a brand's flagship store; the dark solid line passes the centroid of the circle dots and its slope illustrates the estimated mean of own price elasticity (for all flagship stores of prominent brands) from Table 5. Other dots and lines are constructed in a similar way for B2C and C2C stores: for each brand, we construct an aggregated "average" store for $\mathrm{C} 2 \mathrm{C}$ (blue diamond/dash) and $\mathrm{B} 2 \mathrm{C}$ store (red cross/shortdash), respectively.

Recall from the demand estimation, we find own elasticities to be the largest for flagship stores, followed by $\mathrm{B} 2 \mathrm{C}$ and then $\mathrm{C} 2 \mathrm{C}$. That means the black line of elasticity (for flagship) is flatter than the blue line (for $\mathrm{B} 2 \mathrm{C}$ ) and the red line (for $\mathrm{C} 2 \mathrm{C}$ ). Rather remarkably, this order is consistent with the order of the slopes (not depicted) implied by the raw observed prices and quantities: for flagship stores, we see the dark circles concentrated in a tight band of price but dispersed across a large range of quantity, which implies a rather flat line if we fit them into a linear model. In contrast, the raw data for $\mathrm{C} 2 \mathrm{C}$ varies over a larger range of price but a tighter range of quantity than flagship stores, implying a much steeper fitted line. B2C is somewhere between the two, just as our estimated own elasticities. Analogously, Figure 9 shows a similar pattern for non-prominent brands. Hence, the general result that $\mathrm{C} 2 \mathrm{C}$ sellers being less elastic than Flagship/B2C ones is likely driven by a feature in the raw

\footnotetext{
higher quality with prominent brands.

${ }^{9}$ These results and discussions on price elasticity across channels may be specific to Category A.

${ }^{10}$ Unfortunately, we do not know what other products a store sells beyond Category A, so it is difficult to confirm this story.
} 
data instead of being an artifact of the model.

Finally, in Table 5, we also show the cross elasticities among the product groups categorized by channel and brand type (prominent or non-prominent), where the group elasticity of group $X$ with respect to $Y$ is defined as the effect of a percentage change in all the prices of group $X$ on the total share of group $Y$. We can see that: 1) the substitution within prominent or non-prominent brands is much stronger than that between prominent and non-prominent ones; 2) B2C sellers are on average closer substitutes for flagship store than $\mathrm{C} 2 \mathrm{C}$ sellers. As we shall see in the counterfactual simulations, these substitution patterns play a major role in determining the business stealing (across-brand) and cannibalization (within-brand) effects caused by flagship entry.

\subsection{Robustness Checks}

We have performed a bunch of robustness checks on demand estimation. Appendix Tables 10 and 11 try two nesting structures different from Figure 6. Results suggest that these alternative specifications are likely mis-specified. In Appendix Table 12, we report demand estimates while treating price as exogenous. Compared with Table 3, the price coefficients Appendix Table 12 are all negative, but their absolute magnitudes are slightly larger for prominent brands and slightly smaller for non-prominent brands. Appendix Table 13 reports demand estimates from the full sample, including the observations with frequent zero market shares. They do demonstrate attenuation bias as expected. To check whether our results are driven by the annual sales event, Appendix Table 14 excludes from the sample the month corresponding to the platform's annual shopping festival and finds similar results. Appendix Table 15 follows the classical nested logit structure, by forcing the nesting parameters to be the same across channels and brand type. Though point estimates change because of this constraint, results suggest similar price elasticities as in the main results. Appendix A.6 allows the coefficient of log (price) to be random, but results suggest that only the "Prominent-Flagship" group has a statistically significant (estimated) standard deviation of the random coefficient, and its magnitude is rather small comparing to the mean of the random coefficient. ${ }^{11}$ Moreover, the magnitudes of the mean of the random coefficients still demonstrate the same order of price elasticities as in the main results, suggesting that heterogeneity in price sensitivity does not explain why consumer demand is more elastic for flagship and $\mathrm{B} 2 \mathrm{CC}$ stores than for $\mathrm{C} 2 \mathrm{C}$ stores.

\footnotetext{
${ }^{11}$ The estimated mean of the random coefficient on price is very close to the non-random one in the baseline results in Table 3. This is in line with the recent findings in Lu (2022) that non-random coefficient logit (or nested logit) model is robust to the misspecification of random coefficients (e.g., ignoring them) in the sense that it yields a consistent estimate for the mean of random coefficients if they were present in the underlying data generating process.
} 
Appendix Figure 16 demonstrates the goodness of model fit for our main demand specification. For all the months in our sample, we compare the actual and fitted quantities sold, on average, by channel (flagship, B2C, C2C) and brand type (prominent or not) respectively. To keep the platform's business secret, all graphs are normalized by the maximum observed in the raw data. As shown in Appendix Figure 16, the model fit is the best for flagship stores, followed by $\mathrm{B} 2 \mathrm{C}$ and then $\mathrm{C} 2 \mathrm{C}$. The fit is also better for prominent brands than for non-prominent brands.

Two reasons may explain the seemingly large prediction error for an average $\mathrm{C} 2 \mathrm{C}$ seller: first, on average, each $\mathrm{C} 2 \mathrm{C}$ seller has a much smaller quantity sold than a $\mathrm{B} 2 \mathrm{C}$ seller or a flagship store. As a result, the scale of the vertical axis is much more detailed for $\mathrm{C} 2 \mathrm{C}$ sellers in the bottom two graphs. In fact, the seemingly large gap between the actual and fitted quantities of an average $\mathrm{C} 2 \mathrm{C}$ seller represents little absolute difference. Second, because our demand system builds in an $\mathrm{AR}(3)$ error structure (throughout the life time of a product defined by brand-seller-year), we have more missing values in the fitted quantity at the beginning of a product's life time. In our data, there are more frequent entries and exits in $\mathrm{C} 2 \mathrm{C}$ Market than in B2C Market, so these missing values are more prevalent for $\mathrm{C} 2 \mathrm{C}$ Market. This creates more discrepancy between the actual and fitted quantities for an average C2C seller, and as expected, the discrepancy declines steadily over time. Overall, our demand system does a reasonable job predicting the average quantities sold by time, by channel, and by brand type.

\section{Supply Side Model and Estimation}

\subsection{Model}

We assume that B2C and $\mathrm{C} 2 \mathrm{C}$ sellers behave as "single-product firms" such that each product $j$ in market $t$ maximizes its own profit, i.e.,

$$
\max _{P_{j t}}\left(P_{j t}-M C_{j t}\right) Q_{j t}\left(\mathbf{P}_{t}\right)
$$

where $Q_{j t}(\cdot)$ is the quantity demand function of $j, \mathbf{P}_{t}$ is the vector of all the prices in market $t, M C_{j t}$ is the marginal cost.

In contrast, flagship stores are "vertically integrated" and they not only care about their own profit, but may also take into account the wholesale profits from the $\mathrm{B} 2 \mathrm{C} / \mathrm{C} 2 \mathrm{C}$ sales of their brands. Unfortunately, we do not observe wholesale prices or manufacture costs. Conversations with multiple people working in the industry suggest that (1) a flagship store's 
wholesale price (charged to $\mathrm{B} 2 \mathrm{C} / \mathrm{C} 2 \mathrm{C}$ sellers) is often a fixed percentage of its flagship retail price; (2) manufacturing costs for the products in our study category only account for a small fraction of the retail price; and (3) manufacturing costs are similar across brands within the prominent or non-prominent groups (i.e., differences in marginal costs are mostly driven by costs related to retail services, marketing, etc, not costs of production). These industrial practices imply that the profit margin that a brand would earn in wholesale can be approximated as a fixed share of its flagship retail price, especially after we control for the common production costs via brand-year fixed effects.

Specifically, we assume that flagship store $j$ (or store-brand-year $j$ ) in market $t$ solves the following problem

$$
\begin{aligned}
\max _{P_{j t}} & \left\{\left(P_{j t}-M C_{j t}\right) Q_{j t}\left(\mathbf{P}_{t}\right)\right. \\
& \left.+\varphi_{B 2 C} P_{j t} \sum_{k \in \mathcal{B}_{j t}^{B 2 C}} Q_{k t}\left(\mathbf{P}_{t}\right)+\varphi_{C 2 C} P_{j t} \sum_{k \in \mathcal{B}_{j t}^{C 2 C}} Q_{k t}\left(\mathbf{P}_{t}\right)\right\},
\end{aligned}
$$

where $\mathcal{B}_{j t}^{B 2 C}$ and $\mathcal{B}_{j t}^{C 2 C}$ are the sets of products that are of the same brand as $j$ on $\mathrm{B} 2 \mathrm{C}$ and $\mathrm{C} 2 \mathrm{C}$ markets, respectively, and $\varphi_{B 2 C}$ and $\varphi_{C 2 C}$ measure how the flagship store(brand) incorporates the sales from $\mathrm{B} 2 \mathrm{C} / \mathrm{C} 2 \mathrm{C}$ stores selling the same brand. In other words, $\varphi_{B 2 C} P_{j t}$ and $\varphi_{C 2 C} P_{j t}$ are the fixed profit margins that flagship stores may earn from the brands' $\mathrm{B} 2 \mathrm{C} / \mathrm{C} 2 \mathrm{C}$ sales.

The specification of flagship store's profit function (7) differs from a commonly seen model in which flagship store would internalize the profits of $\mathrm{B} 2 \mathrm{C} / \mathrm{C} 2 \mathrm{C}$ stores (see, among others, Ciliberto and Williams (2014) and Sudhir (2001a)). We think the former is better at describing flagship stores' incentives in our context and use it for the baseline results in the main text. However, we consider the latter specification in Appendix B as a robustness check and it yields virtually the same results as the baseline case.

Profit maximization problems (6) and (7) imply a set of first-order conditions (FOCs) that will be used in the estimation of supply side parameters. The FOCs for $\mathrm{B} 2 \mathrm{C} / \mathrm{C} 2 \mathrm{C}$ stores 
are standard and that for a flagship store is

$$
\begin{aligned}
& P_{j t}+\left(\frac{\partial Q_{j t}}{\partial P_{j t}}\right)^{-1} Q_{j t} \\
= & M C_{j t}+\varphi_{B 2 C}\left(\frac{\partial Q_{j t}}{\partial P_{j t}}\right)^{-1}\left[\sum_{k \in \mathcal{B}_{j t}^{B 2 C}}\left(\frac{\partial Q_{k t}}{\partial P_{j t}}+Q_{k t}\right)\right] \\
+ & \varphi_{C 2 C}\left(\frac{\partial Q_{j t}}{\partial P_{j t}}\right)^{-1}\left[\sum_{k \in \mathcal{B}_{j t}^{C 2 C}}\left(\frac{\partial Q_{k t}}{\partial P_{j t}}+Q_{k t}\right)\right] .
\end{aligned}
$$

Now we can use (8) to estimate $\varphi_{B 2 C}$ and $\varphi_{C 2 C}$. To do this, we parameterize the marginal cost of flagship stores linearly as

$$
M C_{j t}^{F S}=\gamma_{j}^{F S}+\tau_{t}^{F S}+\zeta_{j t}
$$

where $\gamma_{j}^{F S}$ and $\tau_{t}^{F S}$ are product and month fixed-effects, and then impose the following moment condition

$$
E\left[\zeta_{j t} Z_{j t}^{S}\right]=0
$$

where $Z_{j t}^{S}$ includes product and month dummies, as well as the first order lags of the last two terms in (8) (without $\varphi_{B 2 C}$ and $\varphi_{C 2 C}$ ).

After estimating $\varphi_{B 2 C}$ and $\varphi_{C 2 C}$, we can compute the implied marginal cost for products sold by flagship stores using (14). Similarly, based on (13), we can obtain the marginal costs of products from $\mathrm{B} 2 \mathrm{C}$ and $\mathrm{C} 2 \mathrm{C}$ stores.

\subsection{Estimation Results}

Table 6 shows the parameter estimates of $\varphi_{B 2 C}$ and $\varphi_{C 2 C}$, as well as a summary of the implied marginal costs for different channels and brand types. We can see that only $\hat{\varphi}_{B 2 C}$ for nonprominent brand is marginally significant (with a p-value close to $8 \%$ ), which suggests that a non-prominent flagship store may take B2C sellers' sales into weak consideration when maximizing its profit. However, overall the evidence that a flagship store internalizes the $\mathrm{B} 2 \mathrm{C} / \mathrm{C} 2 \mathrm{C}$ sales of the same brand is rather weak.

Results on marginal costs show that for prominent brands, flagship stores have much higher marginal costs than $\mathrm{B} 2 \mathrm{C}$ and $\mathrm{C} 2 \mathrm{C}$ ones, with $\mathrm{C} 2 \mathrm{C}$ 's marginal cost being even negative for prominent brands. On the contrary, for non-prominent brands, the differences among the three channels are much smaller and all marginal costs are positive.

There are at least two reasons for the discrepancy in the model-implied marginal costs 
between flagship, B2C and $\mathrm{C} 2 \mathrm{C}$ stores. First, for a given brand, the actual marginal costs can be different, e.g., different stores may carry different sets of items as a way of differentiation: the flagship store typically sells high-end, expensive items while a $\mathrm{C} 2 \mathrm{C}$ seller may only carry low-end, inexpensive ones. The flagship store may also incorporate the opportunity costs of earning a wholesale margin should it shift the same product to another retail outlet beyond the platform. Second, even if the actual costs are the same, comparing to the flagship store, a $\mathrm{C} 2 \mathrm{C}$ (or $\mathrm{B} 2 \mathrm{C}$ ) seller may have a stronger incentive to adopt a loss-leader strategy, i.e., charge a lower price than the (static) profit-maximizing level to acquire market share and accumulate reputation. ${ }^{12}$ In this case, it appears as if the $\mathrm{C} 2 \mathrm{C}$ seller can earn a marginal benefit by selling a product of a prominent brand. Hence, the effective (model-implied) marginal cost of the $\mathrm{C} 2 \mathrm{C}$ seller is lower than that of the flagship store.

Although the estimated negative marginal costs for some products can be somewhat rationalized based on the above interpretations, they do signify an important issue of profit maximization with inelastic demand: the objective function in (6) is not concave but instead increasing in price. This issue will result in non-convergence of the computation of market equilibria in the counterfactual analysis.

One solution to the problem is to extend the current model in a way that it can account for sellers' incentives beyond the static profit maximization, e.g., marginal benefit of sales/reputation mentioned above. However, without additional data and information, this type of extension is based on conjecture and rather arbitrary. Hence, we decide to use a simple, ad-hoc fix to the problem of non-concave profit function.

In particular, we impose a "reduced-form" upper bound on the prices of the inelastic products to restore concavity of the profit function, i.e.,

$$
P_{j t} \leq \bar{P}_{j t}=\exp \left(W_{j t}^{\prime} \rho\right)
$$

where $W_{j t}$ is a vector of explanatory variables and $\rho$ is the unknown parameter to be estimated. It follows that the observed prices of the inelastic products are simply the upper bound $\bar{P}_{j t}$. Thus, we can use the coefficients in Panel I of Table 2 as the estimated $\rho$ when needed. Because we only run into negative marginal costs for $\mathrm{C} 2 \mathrm{C}$ sellers of prominent brands, this "reduced-form" fix only applies to these sellers.

\footnotetext{
${ }^{12} \mathrm{~A}$ recent research by Fan et al. (2016) uses C2C data to show that the return from reputation can be rather substantial.
} 


\section{Counterfactual Analysis}

In this section, we apply the estimated model to simulate the effects of flagship entry on the market outcome. Specifically, for each brand that does not have a flagship store by the end of our sample period, we assume the brand opens one at the beginning of the last month and calculate the new market equilibrium, which is then compared with the actual data to examine the effects. Then we repeat the above analysis for all the brands that do not have flagship stores. As a recap, a quick summary of the last month's data is in Table 1.

\subsection{Baseline Case}

To simulate a hypothetical entry of a flagship store, we add the store to the market $t$ as the $\left(J_{t}+1\right)$-th product and compute the new equilibrium prices and quantities based on the following iterative procedure:

$$
\begin{aligned}
& s_{j t}^{r+1}=\exp \left[\delta_{j t}^{\text {post }}-\alpha_{j} \log \left(P_{j t}^{r}\right)\right] \cdot\left(s_{c \mid b, t}^{r}\right)^{\lambda_{b, j}} \cdot\left(s_{j \mid b c, t}^{r}\right)^{\lambda_{b c, j}} s_{0 t}^{r} \\
& P_{j t}^{r+1}=1\left(e_{j t}\left(\mathbf{s}_{t}^{r}\right)>1\right)\left[M C_{j t}^{p o s t}+\frac{P_{j t}^{r}}{e_{j t}\left(\mathbf{s}_{t}^{r}\right)}+I_{j t}^{N P, F S} \hat{\varphi}_{B 2 C} g_{j t}\left(\mathbf{s}_{t}^{r}\right)\right]+1\left(e_{j t}\left(\mathbf{s}_{t}^{r}\right)<1\right) \bar{P}_{j t}^{\text {post }}
\end{aligned}
$$

for all $j=1, \ldots, J_{t}+1$,

where $r$ labels a step in the iteration, $e_{j t}\left(\mathbf{s}_{t}^{r}\right)$ is the price elasticity (absolute value), $I_{j t}^{N P, F S}$ is an indicator for non-prominent flagship store (recall that the only significant conduct parameter estimate is $\hat{\varphi}_{B 2 C}$ for non-prominent flagship stores), $g_{j t}\left(\mathbf{s}_{t}^{r}\right)$ refers to the second term (without $\varphi_{B 2 C}$ ) on the RHS of equation (8), $\delta_{j t}^{\text {post }}, M C_{j t}^{\text {post }}$ and $\bar{P}_{j t}^{\text {post }}$ are the post-entry mean utility, marginal cost and upper bound on price, respectively. Note that the price equation in (10) takes the previously mentioned issue of inelastic products into account: an inelastic product's price is updated using the reduced-form upper bound.

For an "incumbent product", $M C_{j t}^{\text {post }}$ is the same as the pre-entry marginal cost, while $\delta_{j t}^{\text {post }}$ and $\bar{P}_{j t}^{\text {post }}$ are adjusted (because the variables describing the flagship entry change) based on the demand estimation results (Table 3 and 4) and the upper bound on price (for inelastic products).

For the entering flagship store, we assume that $M C_{j t}^{p o s t}$ (and $\delta_{j t}^{\text {post }}$ ) equals to the mean of that of incumbent flagship stores that have the same brand type (prominent or nonprominent) as the entering one. This assumption can be challenged by a potential selection bias, if brands that opened a flagship store early had expected higher profits from the flagship entry, or had anticipated their flagship store to carry a higher quality premium in consumer perception. 
Fortunately, we can test this concern in the data. Panel A of Figure 17 presents a scatter plot of the timing of each flagship entry and the profits of that flagship store as predicted by our demand and cost estimates. Their correlation is very small (0.001). If anything, the positive correlation suggests that earlier flagship entrants have slightly lower profits, which is against the selection bias. Panel B of Figure 17 shows the correlation between the timing of flagship entry and the estimated brand-flagship fixed effects. ${ }^{13}$ Again, the correlation is very weak (-0.023), though its sign is consistent with the selection concern. Combined, these two figures provide little support for the potential selection bias in the timing of flagship entry.

As an additional sanity check of the assumption, we try predicting the $\delta_{j t}^{\text {post }}$ of the hypothetically entering flagship store in a way that can account for its brand-specific effect. In particular, we regress the demand residual defined in (5) on brand and channel dummies (controlling for year-month FEs) and then use the fitted model to predict $\delta_{j t}^{\text {post }}$, which is then used in the simulation. The simulation results are virtually the same as the the above simple version of using average $\delta_{j t}^{\text {post }}$ of incumbent flagship stores, so they are not shown here to conserve space.

After computing the post-entry equilibrium price and demand, we can calculate the changes in consumer surplus using the following formula (derived from our nested-logit demand model),

$$
\Delta C S_{t}=\hat{\Gamma}_{t}\left[\log \left(1+I_{t}^{\text {post }}\right)-\log \left(1+I_{t}^{\text {pre }}\right)\right],
$$

where $\hat{\Gamma}_{t}=\frac{1}{J_{t}} \sum_{j=1, \ldots, J_{t}} \frac{P_{j t}^{p r e}}{\hat{\alpha}_{j}}$ measures the inverse of willingness-to-pay, and

$$
I_{t}^{k}=\sum_{b \in \mathcal{B}_{t}}\left(I_{b, t}^{k}\right)^{1-\lambda_{b}}, I_{b, t}^{k}=\sum_{c \in \mathcal{C}_{b, t}}\left[\left(I_{b c, t}^{k}\right)^{1-\lambda_{b c}}\right]^{\frac{1}{1-\lambda_{b}}}, I_{b c, t}^{k}=\sum_{j \in \mathcal{J}_{b c, t}} \exp \left(\frac{\delta_{j t}^{k}-\alpha_{j} \log \left(P_{j t}^{k}\right)}{1-\lambda_{b c}}\right)
$$

for $k \in\{$ post-entry, pre-entry\}. Also, given our supply model, stores' profits can be calculated easily.

The counterfactual simulation results are summarized in Table 7. Panel A and B respectively show the average outcomes for the flagship entries of the prominent and non-prominent brands that do not own flagship stores (in the Category A). Within each panel, we summarize the changes of the entrants themselves and incumbents across different channels. Table 7 suggests five patterns:

First, for the entering flagship store (entrant), both its price and quantity are greater than those (quantity-weighted average price and total quantity) of the other products (brand-

\footnotetext{
${ }^{13}$ In case a brand-flagship has appeared in our data for more than one year, we take the average of its brand-flagship-year fixed effects in Figure 17.
} 
seller-year) within the same brand. Similar results hold for profit and GMV comparisons. These results illustrate the rather strong demand for flagship stores, implying that a potential flagship entrant may find it very profitable to enter the platform.

Second, with regard to the within-brand incumbent sellers, there is a clear price reduction because the flagship entry intensifies price competition (except for the case of $\mathrm{C} 2 \mathrm{C}$ and nonprominent brand, where the price effect is zero). However, even with the price reduction, within-brand incumbents lose sales due to strong cannibalization. Their GMV and profits go down accordingly.

Third, the effects on incumbents of other brands are somewhat different for prominent and non-prominent entry. If the entry is a prominent flagship, it tends to negatively affect the $\mathrm{C} 2 \mathrm{C}$ sellers of other brands, drive down the price and profits of other flagship stores, but help the $\mathrm{B} 2 \mathrm{C}$ sellers of other brands. But if the entry is a non-prominent flagship, it has a universal positive effect on flagship, B2C and $\mathrm{C} 2 \mathrm{C}$ sellers of other brands. This confirms the reduced-form evidence that market expansion effects are more likely driven by non-prominent flagship entries than by prominent entries.

Fourth, overall the platform benefits from the flagship entry: the total platform GMV increases about 0.08 and 0.6 percent for a prominent and a non-prominent flagship entry, respectively. This suggests that, on average, the platform welcomes both types of flagship entries. But if it has to choose between the two, it would prefer a non-prominent entry, probably because prominent entries have a bigger cannibalization effect, tend to lower consumer willingness to pay for $\mathrm{C} 2 \mathrm{C}$ sellers, and do not generate as much market expansion effects on other brands.

Fifth, total consumer surplus increases upon a non-prominent flagship entry, but decreases upon a prominent flagship entry. This difference occurs because, after a prominent brand opens a flagship store, consumers lower their willingness to pay for $\mathrm{C} 2 \mathrm{C}$ sellers of both the entry brand and other brands. To the extent that this downward adjustment represents a correction of consumer perception, it is not necessarily a real utility loss and could even be beneficial to consumers.

To further understand exactly what drives these effects, Table 8 compares the baseline results of Table 7 with two hypothetical columns ${ }^{14}$ : the first column artificially shuts down the entry's direct within-brand effects (i.e. in Table 3, setting the coefficient of own flagship store as zero) and direct across-brand effects (i.e. in Table 4, setting the coefficients of the number of prominent and non-prominent flagship entries as zero). In doing so, what is left in this column is the flagship entry expanding consumer's choice set for the entry brand and triggering a new price equilibrium without any change on all the other product fixed effects.

\footnotetext{
${ }^{14}$ The full set of results for these two columns are reported in Appendix Tables 18 and 19.
} 
As expected, the bigger choice set will intensify price competition, cannibalize same-brand sellers, and boost consumer surplus. The platform's GMV has a very modest increase (less than $0.01 \%$ per entry), and these effects are similar for prominent and non-prominent brands.

The second hypothetical column in Table 8 only shuts down the direct across-brand effects from the flagship entry. Compared to the first column, it allows the flagship entry to affect consumer perception of same-brand products sold by $\mathrm{C} 2 \mathrm{C}$ and $\mathrm{B} 2 \mathrm{C}$ sellers. From Table 3, we know flagship entries make consumers more skeptical about $\mathrm{C} 2 \mathrm{C}$ sellers of the same brand. This negative effect ends up erasing all the consumer surplus gains from the first column, with little influence on the entering flagship's profits or the platform's GMV. From this second column to the overall baseline effects, we add back the direct effect of the flagship entry on other brands. Because prominent entries cast doubt on the quality of C2C sellers but boost consumer confidence of B2C sellers, this addition drives down consumer surplus, increases the profits of B2C sellers, and overall improves the platform's GMV. In comparison, if the flagship entry is from a non-prominent brand, it always has a positive effect on consumer perception of other brands, which pushes up the overall consumer surplus, the profits of incumbent sellers of other brands, and the platform's GMV.

\subsection{Flagship Entry with Restrictions on Other Sellers that Sell the Same Brand}

In the baseline case, we simulate flagship entry while assuming all the other sellers stay on the market and their marginal costs do not change. However, it is possible that the entering flagship, representing its brand, may request a collaboration with the platform on raising service level standard or restricting the resale rights of other sellers selling the same brand. In this subsection, we simulate several cases where a flagship entry is associated with restrictions on other same-brand sellers.

Specifically, we consider three potential scenarios when the flagship of a brand enters the market: 1) individual sellers on $\mathrm{C} 2 \mathrm{C}$ Market are banned from selling the brand; 2) business sellers on B2C Market are banned from selling the brand; 3) only the top $10 \%$ (in terms of GMV) of the brand's C2C and B2C sellers respectively are allowed to sell the brand. To our best knowledge, the platform has not introduced any third-party restrictions in any flagship entry. ${ }^{15}$ So all these counterfactuals are hypothetical.

The results are summarized in Table 9. We only highlight the effects on within-brand incumbents, as the results on sellers of other brands are virtually the same as those in the

\footnotetext{
${ }^{15}$ This observation is based on conversation with the platform's employees. We cannot observe any specific contract between the platform and the brands regarding flagship entry.
} 
baseline case (Table 7$).{ }^{16}$

As shown in Table 9, the entering flagship store benefits substantially from restricting other sellers in terms of GMV and profits, especially for the cases of banning C2C sellers and keeping top sellers. This is not surprising because of the within-brand demand substitution from those banned sellers to the flagship store.

For the case of banning $\mathrm{C} 2 \mathrm{C}$ sellers, the profit of the surviving $\mathrm{B} 2 \mathrm{C}$ stores increase substantially, even more than $100 \%$ for non-prominent flagship entries. This is because for many brands, B2C Market's quantity/GMV are much smaller than C2C Market's, so the substitution from C2C Market to B2C Market, measured by B2C Market's quantity/GMV, appears to be very large. Moreover, the total change in quantity/GMV of $\mathrm{C} 2 \mathrm{C}$ and $\mathrm{B} 2 \mathrm{C}$ Market combined is around $-90 \%$ so we can expect a sizeable consumer welfare loss.

Comparing to the case of banning $\mathrm{C} 2 \mathrm{C}$ sellers, removing $\mathrm{B} 2 \mathrm{C}$ sellers has a smaller impact. For example, the flagship's cannibalization effects on $\mathrm{C} 2 \mathrm{C}$ stores is only slightly mitigated by the demand substitution from $\mathrm{B} 2 \mathrm{C}$ stores to $\mathrm{C} 2 \mathrm{C}$ sellers.

For the case of keeping top sellers in $\mathrm{C} 2 \mathrm{C}$ and $\mathrm{B} 2 \mathrm{C}$ Market, the overall $\mathrm{C} 2 \mathrm{C}$ (or $\mathrm{B} 2 \mathrm{C}$ ) quantity/GMV decreases around $70 \%$ while the surviving top sellers benefit from restricting fringe ones from the platform. These different types of restrictions always lead to a lower overall consumer welfare than the baseline, unrestricted case. As shown in Figures 12 and 13, the whole distribution of consumer surplus change - across all the counterfactuals of each prominent and non-prominent flagship entry - shifts to the left when we impose seller restrictions. This is intuitive as consumers prefer a larger choice set and the intensified competition within the choice set.

In general, the restrictions could lead to lower, equivalent, or higher GMV for the platform. This is because of two countervailing forces: on one hand, higher price, higher sales, and higher profits of the flagship store would benefit the platform; on the other hand, due to reduced competition, the quantity that would have been sold by banned sellers are not fully compensated by the flagship store and surviving sellers, which hurts the platform. For an average prominent flagship entry, the former exceeds the latter, resulting in platform GMV being higher than or equivalent to the baseline, unrestricted case. By contrast, for an average non-prominent flagship entry, the latter dominates the former, resulting in lower GMV for the platform if the entry is accompanied with any seller restriction. That been said, if we compare the distribution of platform GMV change with and without seller restrictions (Figures 10 and 11), we see both positive and negative GMV changes even within prominent or non-prominent flagship entries. This suggests that the direction of GMV change is more brand-specific than brand-type-specific.

\footnotetext{
${ }^{16}$ Appendix Table 20 reports the full set of results for these three restricted scenarios.
} 


\section{Conclusion}

To conclude, we study one cosmetic category in a large online marketplace to understand the impact of a popular form of online-offline retail known as flagship entry. We find that, on a popular e-commerce platform, flagship entry cannibalizes the sales of other sellers within the same brand, but expands the market for some parts of the platform. Flagship entry could be win-win-win for the brand, the platform and consumers as a whole, because product variety is improved, price competition is intensified, and the overall market is expanded.

We also find meaningful difference between prominent and non-prominent brands. Upon a prominent flagship entry, consumers tend to put a high premium on the entering flagship store but lower their willingness to pay for $\mathrm{C} 2 \mathrm{C}$ sellers (of same and other brands). This translates to a drop in consumer surplus, although a correction on perception (of C2C sellers) could be beneficial to consumers. In comparison, flagship entry of a non-prominent brand generates universal positive spillovers on all types of sellers of other brands, resulting in a greater market expansion effect than a prominent flagship entry. On average, this translates into greater improvement in consumer surplus and platform GMV.

The flagship premium as reflected by our data can be driven by multiple mechanisms. Some consumers may hold an inherent belief that flagship store offers better quality and better variety of products/services than $\mathrm{B} 2 \mathrm{C}$ and $\mathrm{C} 2 \mathrm{C}$ sellers of the same brand. Flagship entry simply allows these consumers to reveal their preferences. Another possibility is that the platform's search ranking algorithm gives more visibility to flagship stores than to B2C and $\mathrm{C} 2 \mathrm{C}$ sellers. Unfortunately, we do not have access to any search or ranking data of the study platform and therefore cannot address this mechanism directly. However, since the platform earns commission from all realized sales, it is not in the platform's interests to suppress a listing that consumers want to see. To the opposite, the platform has incentives to facilitate consumer search and present the listings that best match consumer demand. A third possibility is that flagship stores advertise more on the platform than $\mathrm{B} 2 \mathrm{C}$ and $\mathrm{C} 2 \mathrm{C}$ stores. Without any advertising data, we cannot distinguish the effect of advertising from other mechanisms. Throughout the paper, we interpret the "utility" that consumers derive from flagship as consumer preferences, while recognizing that these preferences may reflect multiple factors that contribute to the process of consumer shopping.

Under this interpretation, counterfactual simulations suggest that consumer welfare would be reduced if flagship entry were accompanied by constraints on other same-brand sellers, as compared to the no-restriction baseline. This is because constraints such as limiting individual sellers, limiting business sellers, or only keeping top sellers on the platform would reduce within-brand competition. In other words, adding such third-party restrictions tend 
to benefit the brand that opens a flagship store, but hurt consumers and often the platform as well. This highlights a potential conflict between the brand and the platform when they negotiate the flagship entry contract.

Our research is subject to a few limitations. First, with brand-seller-year fixed effects, we assume the exact timing of each observed flagship entry is exogenous within the calendar year. We believe this is reasonable because individual $\mathrm{C} 2 \mathrm{C}$ and $\mathrm{B} 2 \mathrm{C}$ sellers are unlikely to predict the exact timing of each flagship entry, and we find no evidence for the potential concern that more influential brands may open the flagship store earlier.

Second, to identify the spillover effects of flagship entry on other brands, we rely on the time-series of sales growth on the platform. If such growth is driven by other time-varying changes in consumer demand for Category A, we could have over- or under-estimated the true spillover effects.

Third, our data is limited to one cosmetic category, while many stores carry products in other categories. Because of these data limits, we cannot incorporate store or brand strategies that engage multiple products, multiple categories, or dynamic concerns. Moreover, C2C and $\mathrm{B} 2 \mathrm{C}$ sellers may change their product selection, marketing and other business strategies upon a flagship entry, but we do not model these supply changes explicitly. Our results likely reflect a mixture of demand and supply effects.

Furthermore, we have no data on other retail outlets. It is possible that flagship entry prompts consumers to switch away from traditional retailers or the brand's own website. In that case, traditional retailers and the brand's own website may suffer from the flagship entry, and these changes are not incorporated in our welfare calculation.

Finally, our study focuses on one digital platform that has actively pursued flagship entry in a large scale. This strategy, and the efforts and resources behind it, are likely specific to the platform. For this reason, our quantitative estimates are not generalizable to other digital platforms, though the underlying economics could be similar across platforms.

\section{References}

Arellano, Manuel and Stephen Bond, "Some Tests of Specification for Panel Data: Monte Carlo Evidence and an Application to Employment Equations," The Review of Economic Studies, 04 1991, 58 (2), 277-297.

Berry, S., J. Levinsohn, and A. Pakes, "Automobile prices in market equilibrium," Econometrica: Journal of the Econometric Society, 1995, pp. 841-890. 
Berry, S.T., "Estimating discrete-choice models of product differentiation," The RAND Journal of Economics, 1994, pp. 242-262.

Berry, Steven and Panle Jia, "Tracing the woes: An empirical analysis of the airline industry," American Economic Journal: Microeconomics, 2010, 2 (3), 1-43.

Berry, Steven T and Joel Waldfogel, "Free entry and social inefficiency in radio broadcasting," The RAND Journal of Economics, 1999, 30 (3), 397-420.

Chintagunta, Pradeep K, Andre Bonfrer, and Inseong Song, "Investigating the effects of store-brand introduction on retailer demand and pricing behavior," Management Science, 2002, 48 (10), 1242-1267.

Ciliberto, Federico and Jonathan W. Williams, "Does multimarket contact facilitate tacit collusion? Inference on conduct parameters in the airline industry," The RAND Journal of Economics, 2014.

Dinerstein, Michael, Liran Einav, Jonathan Levin, and Neel Sundaresan, "Consumer Price Search and Platform Design in Internet Commerce," American Economic Review, July 2018, 108 (7), 1820-59.

Doraszelski, Ulrich, Greg Lewis, and Ariel Pakes, "Just Starting Out: Learning and Equilibrium in a New Market," American Economic Review, 2018, 108 (3), 565-615.

Economides, Nicholas, Katja Seim, and V Brian Viard, "Quantifying the benefits of entry into local phone service," the RAND Journal of Economics, 2008, 39 (3), 699-730.

Fan, Ying and Chenyu Yang, "Competition, product proliferation, and welfare: A study of the US smartphone market," American Economic Journal: Microeconomics, 2020, 12 (2), 99-134.

_, Jiandong Ju, and Mo Xiao, "Reputation premium and reputation management: Evidence from the largest e-commerce platform in China," International Journal of Industrial Organization, 2016, 46, $63-76$.

Foncel, Jerome and Marc Ivaldi, "OPERATING SYSTEM PRICES IN THE HOME PC MARKET," The Journal of Industrial Economics, 2005.

Gandhi, Amit, Zhentong Lu, and Xiaoxia Shi, "Estimating Demand for Differentiated Products with Zeroes in Market Share Data," working paper, 2019. 
Grennan, Matthew, "Price Discrimination and Bargaining: Empirical Evidence from Medical Devices," American Economic Review, 2013.

Grossman, Gene M and Carl Shapiro, "Foreign counterfeiting of status goods," The Quarterly Journal of Economics, 1988, 103 (1), 79-100.

Houde, Jean-François, Peter Newberry, and Katja Seim, "Economies of density in e-commerce: A study of Amazon's fulfillment center network," Technical Report, National Bureau of Economic Research 2017.

Jia, Panle, "What happens when Wal-Mart comes to town: An empirical analysis of the discount retailing industry," Econometrica, 2008, 76 (6), 1263-1316.

Lu, Zhentong, "Bayesian Inversion of Demand Systems," Working Paper, 2022.

_, Xiaoxia Shi, and Jing Tao, "Semi-Nonparametric Estimation of Random Coefficient Logit Model for Aggregate Demand," Working Paper, 2022.

McFadden, Daniel, "Modeling the choice of residential location," Transportation Research Record, 1978, (673).

_, "Econometric models of probabilistic choice," Structural analysis of discrete data with econometric applications, 1981, 198272.

Nevo, Aviv, "Measuring Market Power in the Ready-to-Eat Cereal Industry," Econometrica, 2001.

Pauwels, Koen and Shuba Srinivasan, "Who benefits from store brand entry?," Marketing Science, 2004, 23 (3), 364-390.

Petrin, Amil, "Quantifying the benefits of new products: The case of the minivan," Journal of political Economy, 2002, 110 (4), 705-729.

Qian, Yi, "Impacts of entry by counterfeiters," The Quarterly Journal of Economics, 2008, $123(4), 1577-1609$.

Seim, Katja and Joel Waldfogel, "Public monopoly and economic efficiency: evidence from the Pennsylvania liquor control board's entry decisions," American Economic Review, 2013, 103 (2), 831-62.

Sudhir, K., "Competitive Pricing Behavior in the Auto Market: A Structural Analysis," Marketing Science, 2001a. 
_ , "Structural Analysis of Manufacturer Pricing in the Presence of a Strategic Retailer," Marketing Science, 2001b.

Sweeting, Andrew, "Dynamic Product Positioning in Differentiated Product Markets: The Effect of Fees for Musical Performance Rights on the Commercial Radio Industry," Econometrica, 2013.

Verboven, Frank, "International price discrimination in the European car market," The RAND Journal of Economics, 1996, pp. 240-268.

Wollmann, Thomas G, "Trucks without bailouts: Equilibrium product characteristics for commercial vehicles," American Economic Review, 2018, 108 (6), 1364-1406. 


\section{Tables}

Table 1: Summary Statistics for the Last Month (normalized)

\begin{tabular}{ccccccc}
\hline \multirow{2}{*}{ Brand Type } & Channel & $\begin{array}{c}\text { No. of } \\
\text { Products }\end{array}$ & $\begin{array}{c}\text { No. of } \\
\text { Sellers }\end{array}$ & $\begin{array}{c}\text { No. of } \\
\text { Brands }\end{array}$ & $\begin{array}{c}\text { Ave } \\
\text { Price }\end{array}$ & $\begin{array}{c}\text { Ave } \\
\text { Quantity }\end{array}$ \\
\hline \multirow{3}{*}{ Prominent } & C2C & $37.53 N$ & $18.96 N$ & $.15 N$ & $1.24 P$ & $.004 Q$ \\
& B2C & $.59 N$ & $.39 N$ & $.08 N$ & $1.33 P$ & $.05 Q$ \\
& Flagship & & $.10 N$ & & $2.30 P$ & $.85 Q$ \\
\hline \multirow{3}{*}{ Non-Prominent } & C2C & $106.04 N$ & $53.26 N$ & $1.54 N$ & $.94 P$ & $.01 Q$ \\
& B2C & $2.06 N$ & $1.29 N$ & $.56 N$ & $.98 P$ & $.11 Q$ \\
& Flagship & & $N$ & & $P$ & $Q$ \\
\hline
\end{tabular}

Note: This table shows some summary statistics for the last time period in our sample. Average price and quantity are the means across all brand-sellers in the month. The numbers in each column are normalized by the last row (non-prominent flagship store) to mask the real numbers.

Table 2: Reduced-form Effects of Flagship Entry

\begin{tabular}{|c|c|c|c|c|c|c|}
\hline & \multicolumn{2}{|c|}{$\mathrm{C} 2 \mathrm{C}$} & \multicolumn{2}{|c|}{$\mathrm{B} 2 \mathrm{C}$} & \multicolumn{2}{|c|}{ Flagship } \\
\hline & Prominent & Non-Prominent & Prominent & Non-Prominent & Prominent & Non-Prominent \\
\hline & \multicolumn{6}{|c|}{ Panel I: Log(Price) } \\
\hline \multirow[t]{2}{*}{ FS Entry $_{\text {own }}$} & $-0.0187^{* * *}$ & $0.00668^{* * *}$ & $-0.142^{* * *}$ & $0.0749 * * *$ & & \\
\hline & $(0.00159)$ & $(0.000959)$ & $(0.0122)$ & $(0.0103)$ & & \\
\hline \multirow{2}{*}{$N_{\text {prom }}^{F S}$} & $0.000549 * *$ & $0.00138 * * *$ & $0.00593^{* * *}$ & 0.00109 & $-0.00532^{* *}$ & $-0.00740 * * *$ \\
\hline & $(0.000278)$ & $(0.000156)$ & $(0.00181)$ & $(0.000877)$ & $(0.00242)$ & $(0.00142)$ \\
\hline \multirow[t]{2}{*}{$N_{\text {non-prom }}^{F S}$} & $0.000319^{* * *}$ & $-0.0000469^{*}$ & $-0.000927^{* * *}$ & $-0.000862^{* * *}$ & $-0.00232^{* * *}$ & $-0.00146^{* * *}$ \\
\hline & $(0.0000444)$ & $(0.0000250)$ & $(0.000289)$ & $(0.000139)$ & $(0.000378)$ & $(0.000221)$ \\
\hline \multirow[t]{2}{*}{ No. of Obs. } & $1,887,722$ & $3,562,479$ & 11,024 & 53,421 & 2,055 & 24,058 \\
\hline & \multicolumn{6}{|c|}{ Panel II: Log(Quantity) } \\
\hline \multirow[t]{2}{*}{ FS Entry $_{\text {own }}$} & $0.160^{* * *}$ & $0.0106^{* * *}$ & $-0.346^{* * *}$ & $-0.884^{* * *}$ & & \\
\hline & $(0.00398)$ & $(0.00370)$ & $(0.0549)$ & $(0.0470)$ & & \\
\hline \multirow[t]{2}{*}{$N_{\text {prom }}^{F S}$} & $-0.0134^{* * *}$ & $-0.0140 * * *$ & $0.0198^{* *}$ & $0.0117^{* * *}$ & $0.0502^{* * *}$ & $0.0445^{* * *}$ \\
\hline & $(0.000696)$ & $(0.000602)$ & $(0.00811)$ & $(0.00400)$ & $(0.0131)$ & $(0.00521)$ \\
\hline \multirow{2}{*}{$N_{\text {non-prom }}^{F S}$} & $0.00531^{* * *}$ & $0.00689 * * *$ & $0.0128 * * *$ & $0.0152^{* * *}$ & $0.0291^{* * *}$ & $0.0220^{* * *}$ \\
\hline & $(0.000111)$ & $(0.0000963)$ & $(0.00130)$ & $(0.000636)$ & $(0.00205)$ & $(0.000807)$ \\
\hline \multirow[t]{2}{*}{ No. of Obs. } & $1,887,722$ & $3,562,479$ & 11,024 & 53,421 & 2,055 & 24,058 \\
\hline & \multicolumn{6}{|c|}{ Panel III: $\log ($ Total Monthly GMV) } \\
\hline \multirow[t]{2}{*}{$N_{\text {prom }}^{F S}$} & -0.0183 & -0.00455 & 0.0151 & 0.00413 & 0.0486 & 0.0300 \\
\hline & $(0.0125)$ & $(0.0125)$ & $(0.0251)$ & $(0.0180)$ & $(0.0371)$ & $(0.0291)$ \\
\hline \multirow[t]{2}{*}{$N_{\text {non-prom }}^{F S}$} & $0.00793^{* * *}$ & $0.00991^{* * *}$ & $0.0135^{* *}$ & $0.0145^{* * *}$ & $0.0253^{* * *}$ & $0.0215^{* * *}$ \\
\hline & $(0.00186)$ & $(0.00186)$ & $(0.00374)$ & $(0.00268)$ & $(0.00553)$ & $(0.00434)$ \\
\hline No. of Obs. & 54 & 54 & 54 & 54 & 54 & 54 \\
\hline
\end{tabular}

Note: Panel I \& II shows reduced-form regressions of brand-seller-month level quantity (log-scale) and price (log-scale) on the entry of the brand's own flagship store, as well as the total number of flagship stores of prominent and non-prominent brands. Panel III shows the regression of monthly total GMV (log-scale) of the market on the total number of flagship stores of prominent and non-prominent brands. In panel I \& II, year-month and brand-seller FEs are included and observations are weighted by GMV in all the regressions. In Panel III, year-quarter FEs are included. Robust standard errors in parentheses, ${ }^{*} \mathrm{p}<0.10,{ }^{* *} \mathrm{p}<0.05,{ }^{* * *}$ $\mathrm{p}<0.01$. 
Table 3: Demand Estimation Results

\begin{tabular}{|c|c|c|c|c|c|c|}
\hline \multirow[b]{2}{*}{ Parameter } & \multicolumn{3}{|c|}{ Prominent } & \multicolumn{3}{|c|}{ Non-Prominent } \\
\hline & $\mathrm{C} 2 \mathrm{C}$ & $\mathrm{B} 2 \mathrm{C}$ & Flagship & $\mathrm{C} 2 \mathrm{C}$ & $\mathrm{B} 2 \mathrm{C}$ & Flagship \\
\hline \multirow{2}{*}{$\beta_{\log (\text { price })}$} & $-0.194^{* * *}$ & $-0.128^{* *}$ & $-0.819^{* * *}$ & $-0.466^{* * *}$ & $-0.464^{* * *}$ & $-1.139^{* * *}$ \\
\hline & $(0.0190)$ & $(0.0506)$ & $(0.172)$ & $(0.0341)$ & $(0.0619)$ & $(0.102)$ \\
\hline \multirow[t]{2}{*}{$\lambda_{b c}$} & $0.671^{* * *}$ & $0.900 * * *$ & & $0.618^{* * *}$ & $0.807 * * *$ & \\
\hline & $(0.0122)$ & $(0.0159)$ & & $(0.0127)$ & $(0.0253)$ & \\
\hline \multirow[t]{2}{*}{$\lambda_{b}$} & $0.0979 * * *$ & $0.701^{* * *}$ & $0.888^{* * *}$ & $0.109^{* * *}$ & $0.680 * * *$ & $0.720^{* * *}$ \\
\hline & $(0.0102)$ & $(0.0192)$ & $(0.0354)$ & $(0.0104)$ & $(0.0307)$ & $(0.0491)$ \\
\hline \multirow{2}{*}{ FS Entry own $_{\text {ow }}$} & $-0.0195 * * *$ & -0.0130 & & $-0.0718^{* * *}$ & $0.0366^{* *}$ & \\
\hline & $(0.00366)$ & $(0.0180)$ & & $(0.00339)$ & $(0.0147)$ & \\
\hline \multirow[t]{2}{*}{$\rho_{1}$} & $0.927^{* * *} *$ & $0.617^{* * *}$ & $0.642^{* * *}$ & $0.781^{* * *}$ & $0.717^{* * *}$ & $0.709^{* * *}$ \\
\hline & $(0.0105)$ & $(0.0244)$ & $(0.0365)$ & $(0.00568)$ & $(0.0146)$ & $(0.0193)$ \\
\hline \multirow[t]{2}{*}{$\rho_{2}$} & $0.0339 * *$ & $0.363^{* * *}$ & $0.254^{* * *}$ & $0.154^{* * *}$ & $0.166^{* * *}$ & $0.180^{* * *}$ \\
\hline & $(0.0142)$ & $(0.0364)$ & $(0.0588)$ & $(0.00662)$ & $(0.0225)$ & $(0.0223)$ \\
\hline \multirow[t]{2}{*}{$\rho_{3}$} & $-0.0458 * * *$ & 0.00510 & $0.0938^{*}$ & $-0.0239^{* * *}$ & $0.0793^{* * *}$ & $0.0914^{* * *}$ \\
\hline & $(0.00806)$ & $(0.0291)$ & $(0.0549)$ & $(0.00398)$ & $(0.0169)$ & $(0.0172)$ \\
\hline Product FE & $\checkmark$ & $\checkmark$ & $\checkmark$ & $\checkmark$ & $\checkmark$ & $\checkmark$ \\
\hline Year-Month FE & $\checkmark$ & $\checkmark$ & $\checkmark$ & $\checkmark$ & $\checkmark$ & $\checkmark$ \\
\hline Wald test & $401214.57(70)$ & $2.38 \mathrm{E} 07(70)$ & $6.20 \mathrm{E} 6(65)$ & $2.60 \mathrm{E} 8(70)$ & $37408.16(70)$ & $9.00 \mathrm{E} 6(65)$ \\
\hline A-B Test AR(1) & $-34.09(.000)$ & $-12.07(.000)$ & $-6.25(.000)$ & $-52.30(.000)$ & $-17.18(.000)$ & $-17.25(.000)$ \\
\hline A-B Test AR(2) & $.89(.374)$ & $-.21(.835)$ & $-1.09(.275)$ & $2.87(.004)$ & $-0.87(.383)$ & $-.59(.554)$ \\
\hline Hansen test & $4755.53(825)$ & $448.13(690)$ & $91.45(430)$ & $4444.80(825)$ & $1237.61(821)$ & $710.78(555)$ \\
\hline Difference-in-Hansen & $4357.13(786)$ & $439.16(651)$ & $90.95(392)$ & $3986.49(786)$ & $1171.07(782)$ & $661.75(517)$ \\
\hline No. of Obs. & 120,681 & 2,936 & 991 & 277,845 & 16,539 & 9,662 \\
\hline
\end{tabular}

Note: We implement the classic Arellano and Bond (1991)'s first-difference GMM estimator to estimate equation (3) separately for each subsample defined by channel and whether a brand is prominent or not. Price and within-group shares (and their lags) are treated as endogenous variables. Robust standard errors are in parentheses, ${ }^{*} \mathrm{p}<0.10,{ }^{* *} \mathrm{p}<0.05,{ }^{* * *} \mathrm{p}<0.01$.

Table 4: Decomposing the "Residual" in Demand Function

\begin{tabular}{ccccccc}
\hline & \multicolumn{3}{c}{ Prominent } & \multicolumn{3}{c}{ Non-Prominent } \\
\cline { 2 - 7 } Parameter & C2C & B2C & Flagship & C2C & B2C & Flagship \\
\hline$N_{F S, \text { prom }}$ & $-0.00792^{* * *}$ & $0.0140^{* * *}$ & -0.00175 & $-0.00138^{* * *}$ & $0.00633^{* * *}$ & 0.00176 \\
& $(0.000403)$ & $(0.00237)$ & $(0.00415)$ & $(0.000347)$ & $(0.00127)$ & $(0.00217)$ \\
$N_{F S, \text { non-prom }}$ & $0.00342^{* * *}$ & $0.00514^{* * *}$ & $0.00532^{* * *}$ & $0.00350^{* * *}$ & $0.00610^{* * *}$ & $0.00757^{* * *}$ \\
& $(0.0000753)$ & $(0.000434)$ & $(0.000789)$ & $(0.0000616)$ & $(0.000253)$ & $(0.000431)$ \\
Constant & $-11.77^{* * *}$ & $-13.26^{* * *}$ & $-9.440^{* * *}$ & $-11.89^{* * *}$ & $-12.86^{* * *}$ & $-11.10^{* * *}$ \\
& $(0.0360)$ & $(0.215)$ & $(0.384)$ & $(0.0308)$ & $(0.115)$ & $(0.200)$ \\
Product FE & $\checkmark$ & $\checkmark$ & $\checkmark$ & $\checkmark$ & $\checkmark$ & $\checkmark$ \\
Month FE & $\checkmark$ & $\checkmark$ & $\checkmark$ & $\checkmark$ & $\checkmark$ & $\checkmark$ \\
\hline No. of Obs. & 166,196 & 4,059 & 1,366 & 385,270 & 22,879 & 13,323 \\
\hline
\end{tabular}

Note: We regress the "residual", defined by (5), on the number of prominent and non-prominent flagship stores. The constant term is the mean of product fixed effects. Robust standard errors are in parentheses, ${ }^{*} \mathrm{p}<0.10,{ }^{*} *$ $\mathrm{p}<0.05, * * * \mathrm{p}<0.01$. 
Table 5: Estimated Price Elasticities in the Last Month

\begin{tabular}{c|c|c|ccc|ccc}
\hline \multirow{3}{*}{ Brand Type } & \multirow{3}{*}{ Channel } & Mean & \multicolumn{5}{|c}{ Own } & \multicolumn{4}{|c}{ Prominent } & \multicolumn{3}{c}{ Non-Prominent } \\
\cline { 3 - 9 } & & Elasticities & C2C & B2C & FS & C2C & B2C & FS \\
\hline \multirow{3}{*}{ Prominent } & C2C & -.59 & -.1431 & .0101 & .1375 & .0032 & $3.62 \mathrm{E}-4$ & .0025 \\
& B2C & -1.15 & .0036 & -.5916 & .7451 & .0057 & $6.36 \mathrm{E}-4$ & .0043 \\
& Flagship & -4.65 & .0132 & .1961 & -2.9889 & .0233 & .0026 & .0177 \\
\hline \multirow{3}{*}{ Non-Prominent } & C2C & -1.21 & $8.47 \mathrm{E}-4$ & $1.31 \mathrm{E}-4$ & $6.32 \mathrm{E}-4$ & -.3762 & .0198 & .0554 \\
& B2C & -2.09 & .0014 & $2.10 \mathrm{E}-4$ & .0010 & .0278 & -1.1763 & .03875 \\
& Flagship & -2.30 & .0014 & $4.29 \mathrm{E}-4$ & .0010 & .0370 & .0935 & -1.5515 \\
\hline
\end{tabular}

Table 6: Supply Side Estimation Results

\begin{tabular}{|c|c|c|c|c|}
\hline \multicolumn{5}{|c|}{ Conduct Parameter } \\
\hline \multirow{2}{*}{\multicolumn{3}{|c|}{$\hat{\varphi}_{B 2 C}$}} & Prominent & Non-Prominent \\
\hline & & & -3.00 & -.0281 \\
\hline & & & $(7.62)$ & $(.0156)$ \\
\hline \multirow{2}{*}{\multicolumn{3}{|c|}{$\hat{\varphi}_{C 2 C}$}} & .0672 & .0032 \\
\hline & & & $(.1528)$ & $(.0034)$ \\
\hline \multicolumn{5}{|c|}{ Marginal Cost and Markup (Median and 5\% and 95\% Percentiles) } \\
\hline \multirow{5}{*}{ Prominent } & & Flagship & $\mathrm{B} 2 \mathrm{C}$ & $\mathrm{C} 2 \mathrm{C}$ \\
\hline & $\mathrm{MC}$ & 5.12 & .35 & -1.36 \\
\hline & (Normalized) & {$[.62,11.29]$} & {$[-5.60,1.40]$} & {$[-6.59,-.10]$} \\
\hline & Markiun & $14.85 \%$ & $81.33 \%$ & $169.71 \%$ \\
\hline & Мाанир & {$[13.66 \%, 70.05 \%]$} & {$[78.26 \%, 233.05 \%]$} & {$[169.70 \%, 170.55 \%]$} \\
\hline \multirow{4}{*}{ Non-Prominent } & $\mathrm{MC}$ & 1.00 & .86 & .29 \\
\hline & (Normalized) & {$[.14,4.08]$} & {$[.06,2.50]$} & {$[.03,1.14]$} \\
\hline & Markun & $36.80 \%$ & $44.08 \%$ & $82.07 \%$ \\
\hline & NIarkup & {$[24.86 \%, 85.93 \%]$} & {$[41.66 \%, 82.19 \%]$} & {$[82.06 \%, 84.72 \%]$} \\
\hline
\end{tabular}

Note: The MC's are normalized by the MC for the non-prominent, flagship case. For the conduct parameters, the numbers in the parentheses are standard errors. For the marginal cost and markup results, the numbers in the brackets are the $5 \%$ and $95 \%$ percentiles. 
Table 7: Effects of Flagship Entry: Baseline Case

\begin{tabular}{|c|c|c|c|c|c|c|}
\hline \multicolumn{7}{|c|}{ Panel A: Prominent Brands } \\
\hline \multirow{4}{*}{ Entrant } & & \multicolumn{4}{|c|}{2.79} \\
\hline & \multicolumn{2}{|c|}{ Quantity (Normalized) } & \multicolumn{4}{|c|}{3.24} \\
\hline & GMV (Norm & ized) & \multicolumn{4}{|c|}{3.90} \\
\hline & \multicolumn{2}{|c|}{ Profit (Normalized) } & \multicolumn{4}{|c|}{.43} \\
\hline \multirow{6}{*}{ Incumbent } & & \multicolumn{2}{|c|}{ Within Brand } & \multicolumn{3}{|c|}{ Other Brands } \\
\hline & & $\mathrm{B} 2 \mathrm{C}$ & $\mathrm{C} 2 \mathrm{C}$ & FS & $\mathrm{B} 2 \mathrm{C}$ & $\mathrm{C} 2 \mathrm{C}$ \\
\hline & $\% \Delta$ Price & $-13.24 \%$ & $-1.85 \%$ & $-.16 \%$ & $.09 \%$ & $.004 \%$ \\
\hline & $\% \Delta$ Quantity & $-34.21 \%$ & $-15.65 \%$ & $.17 \%$ & $1.75 \%$ & $-.22 \%$ \\
\hline & $\% \Delta \mathrm{GMV}$ & $-42.05 \%$ & $-17.22 \%$ & $.01 \%$ & $1.84 \%$ & $-.21 \%$ \\
\hline & $\% \Delta$ Profit & $-38.22 \%$ & $-16.49 \%$ & $-.11 \%$ & $2.08 \%$ & $-.27 \%$ \\
\hline \multirow{2}{*}{\multicolumn{2}{|c|}{$\begin{array}{c}\% \Delta \text { Overall Consumer Surplus } \\
\% \Delta \text { Overall GMV }\end{array}$}} & \multicolumn{5}{|c|}{$-.02734 \%$} \\
\hline & & \multicolumn{5}{|c|}{$.08111 \%$} \\
\hline \multicolumn{7}{|c|}{ Panel B: Non-Prominent Brands } \\
\hline \multirow{4}{*}{ Entrant } & \multicolumn{2}{|c|}{ Price (Normalized) } & \multicolumn{4}{|c|}{1.55} \\
\hline & \multicolumn{2}{|c|}{ Quantity (Normalized) } & \multicolumn{4}{|c|}{1.25} \\
\hline & \multicolumn{2}{|c|}{ GMV (Normalized) } & \multicolumn{4}{|c|}{1.39} \\
\hline & \multicolumn{2}{|c|}{ Profit (Normalized) } & \multicolumn{4}{|c|}{.52} \\
\hline \multirow{6}{*}{ Incumbent } & & \multicolumn{2}{|c|}{ Within Brand } & \multicolumn{3}{|c|}{ Other Brands } \\
\hline & & $\mathrm{B} 2 \mathrm{C}$ & $\mathrm{C} 2 \mathrm{C}$ & FS & $\mathrm{B} 2 \mathrm{C}$ & $\mathrm{C} 2 \mathrm{C}$ \\
\hline & $\% \Delta$ Price & $-.63 \%$ & $.01 \%$ & $.08 \%$ & $.04 \%$ & $.004 \%$ \\
\hline & $\% \Delta$ Quantity & $-34.27 \%$ & $-14.95 \%$ & $.70 \%$ & $.60 \%$ & $.31 \%$ \\
\hline & $\% \Delta \mathrm{GMV}$ & $-41.45 \%$ & $-15.68 \%$ & $.77 \%$ & $.64 \%$ & $.32 \%$ \\
\hline & $\% \Delta$ Profit & $-44.30 \%$ & $-15.96 \%$ & $.79 \%$ & $.64 \%$ & $.32 \%$ \\
\hline \multirow{2}{*}{\multicolumn{2}{|c|}{$\begin{array}{c}\% \Delta \text { Overall Consumer Surplus } \\
\% \Delta \text { Overall GMV }\end{array}$}} & \multicolumn{5}{|c|}{$.03334 \%$} \\
\hline & & \multicolumn{5}{|c|}{$.60551 \%$} \\
\hline
\end{tabular}

Note: For each brand (that does not have flagship store), we simulate the entry of its flagship store and summarize the outcome. For the entering flagship store, the outcome variables are normalized by those of the within-brand incumbent sellers (average price, total quantity, total GMV, and total profit). For the incumbent sellers, we calculate the GMV-weighted average of percent changes of the outcome variables. Finally, the numbers reported in this table are the averages across these brands. 
Table 8: Decomposing the baseline counterfactual of flagship entry

\begin{tabular}{|c|c|c|c|c|}
\hline Brand type & Effects on & Overall effects & $\begin{array}{l}\text { Shutdown direct within- } \\
\text { and across-brand effects }\end{array}$ & $\begin{array}{c}\text { Shutdown direct } \\
\text { across-brand effects }\end{array}$ \\
\hline \multirow[t]{8}{*}{ Prominent } & Entrant FS profit & 0.43 & 0.42 & 0.43 \\
\hline & Incumbent same-brand $\mathrm{B} 2 \mathrm{C} \% \Delta$ profit & $-38.22 \%$ & $-39.46 \%$ & $-37.93 \%$ \\
\hline & Incumbent same-brand $\mathrm{C} 2 \mathrm{C} \% \Delta$ profit & $-16.49 \%$ & $-14.81 \%$ & $-16.49 \%$ \\
\hline & Incumbent other-brand FS $\% \Delta$ profit & $-0.11 \%$ & $0.0005 \%$ & $0.0005 \%$ \\
\hline & Incumbent other-brand $\mathrm{B} 2 \mathrm{C} \% \Delta$ profit & $2.08 \%$ & $0.02 \%$ & $0.02 \%$ \\
\hline & Incumbent other-brand $\mathrm{C} 2 \mathrm{C} \% \Delta$ profit & $-0.27 \%$ & $0.002 \%$ & $0.002 \%$ \\
\hline & $\Delta$ Consumer surplus & $-0.02738 \%$ & $0.50759 \%$ & $-0.000168 \%$ \\
\hline & $\Delta$ Platform GMV & $0.08111 \%$ & $0.00879 \%$ & $0.00883 \%$ \\
\hline \multirow[t]{8}{*}{ Non-prominent } & Entrant FS profit & 0.52 & 0.51 & 0.52 \\
\hline & Incumbent same-brand $\mathrm{C} 2 \mathrm{C} \% \Delta$ profit & $-44.30 \%$ & $-49.90 \%$ & $-44.29 \%$ \\
\hline & Incumbent same-brand $\mathrm{B} 2 \mathrm{C} \% \Delta$ profit & $-15.96 \%$ & $-9.05 \%$ & $-15.95 \%$ \\
\hline & Incumbent other-brand FS $\% \Delta$ profit & $0.79 \%$ & $0.0005 \%$ & $0.0005 \%$ \\
\hline & Incumbent other-brand $\mathrm{B} 2 \mathrm{C} \% \Delta$ profit & $0.64 \%$ & $0.02 \%$ & $0.02 \%$ \\
\hline & Incumbent other-brand $\mathrm{C} 2 \mathrm{C} \% \Delta$ profit & $0.32 \%$ & $0.002 \%$ & $0.002 \%$ \\
\hline & $\Delta$ Consumer surplus & $0.03312 \%$ & $0.50759 \%$ & $-0.000173 \%$ \\
\hline & $\Delta$ Platform GMV & $0.60551 \%$ & $0.00754 \%$ & $0.00648 \%$ \\
\hline
\end{tabular}

Note: For each brand (that does not have flagship store), we simulate the entry of its flagship store and summarize the outcome. For the entering flagship store, the outcome variables are normalized by those of the within-brand incumbent sellers (average price, total quantity, total GMV, and total profit). For the incumbent sellers, we calculate the GMV-weighted average of percent changes of the outcome variables. Finally, the numbers reported in this table are the averages across these brands. 
Table 9: Comparing baseline counterfactual vs. flagship entry with seller restrictions

\begin{tabular}{|c|c|c|c|c|c|}
\hline Brand type & Effects on & $\begin{array}{l}\text { Baseline: } \\
\text { FS entry }\end{array}$ & $\begin{array}{c}\text { Restriction 1: } \\
\text { Ban C2C sellers }\end{array}$ & $\begin{array}{c}\text { Restriction 2: } \\
\text { Ban B2C sellers }\end{array}$ & $\begin{array}{c}\text { Restriction } 3: \\
\text { Keep top } 10 \% \text { sellers }\end{array}$ \\
\hline \multirow[t]{5}{*}{ Prominent } & Entrant FS profit & 0.43 & 9.09 & 0.59 & 1.21 \\
\hline & Surviving same-brand $\mathrm{B} 2 \mathrm{C} \% \Delta$ profit & $-38.22 \%$ & $36.80 \%$ & - & $73.19 \%$ \\
\hline & Surviving same-brand $\mathrm{C} 2 \mathrm{C} \% \Delta$ profit & $-16.49 \%$ & - & $-16.49 \%$ & $36.19 \%$ \\
\hline & $\Delta$ Consumer surplus & $-0.02738 \%$ & $-0.03376 \%$ & $-0.03377 \%$ & $-0.03135 \%$ \\
\hline & $\Delta$ Platform GMV & $0.08111 \%$ & $0.08359 \%$ & $0.08110 \%$ & $0.08137 \%$ \\
\hline \multirow[t]{5}{*}{ Non-prominent } & Entrant FS profit & 0.52 & 6.83 & 0.70 & 1.69 \\
\hline & Surviving same-brand $\mathrm{B} 2 \mathrm{C} \% \Delta$ profit & $-44.30 \%$ & $143.82 \%$ & - & $82.27 \%$ \\
\hline & Surviving same-brand $\mathrm{C} 2 \mathrm{C} \% \Delta$ profit & $-15.96 \%$ & - & $-15.75 \%$ & $42.97 \%$ \\
\hline & $\Delta$ Consumer surplus & $0.03312 \%$ & $0.02472 \%$ & $0.02475 \%$ & $0.02832 \%$ \\
\hline & $\Delta$ Platform GMV & $0.60551 \%$ & $0.59621 \%$ & $0.60419 \%$ & $0.5995 \%$ \\
\hline
\end{tabular}

Note: For each brand (that does not have flagship store), we simulate the entry of its flagship store. The numbers reported in this table are the averages across these brands. For the entering flagship store, the outcome variables are normalized by those of the within-brand incumbent sellers (average price, total quantity, total GMV, and total profit). The relative change on the average incumbent is computed based on the "survived" sellers given the restrictions. 


\section{Figures}

Figure 1: Monthly GMV in Cosmetics Category

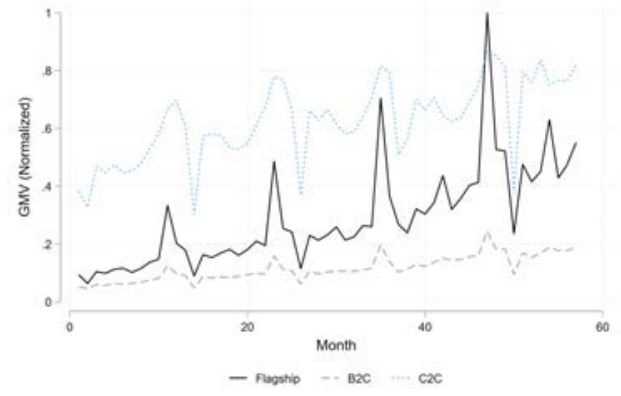

Figure 2: Number of Stores in Cosmetic Category

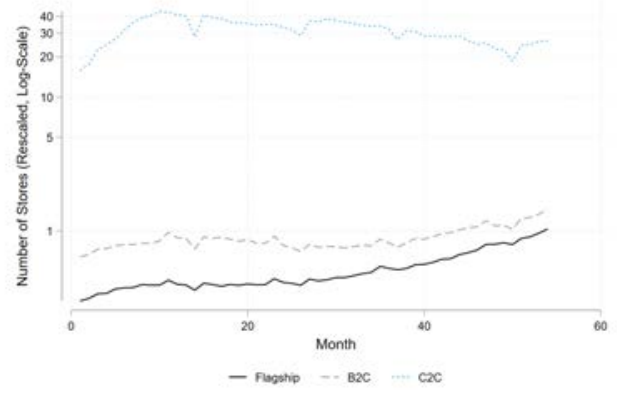

Figure 3: Price Index of Category A

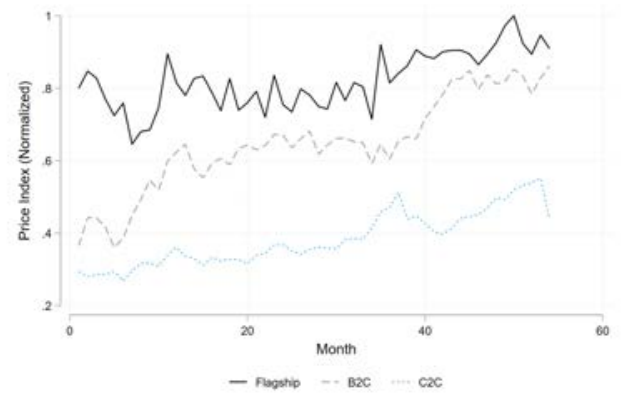

Figure 4: Quantity of Category A

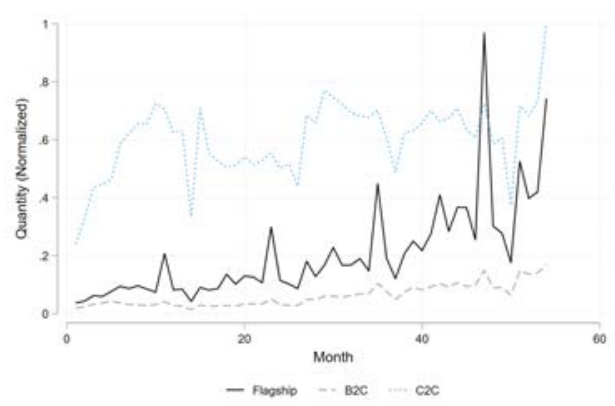


Figure 5: Fraction of Brands with Flagship Stores

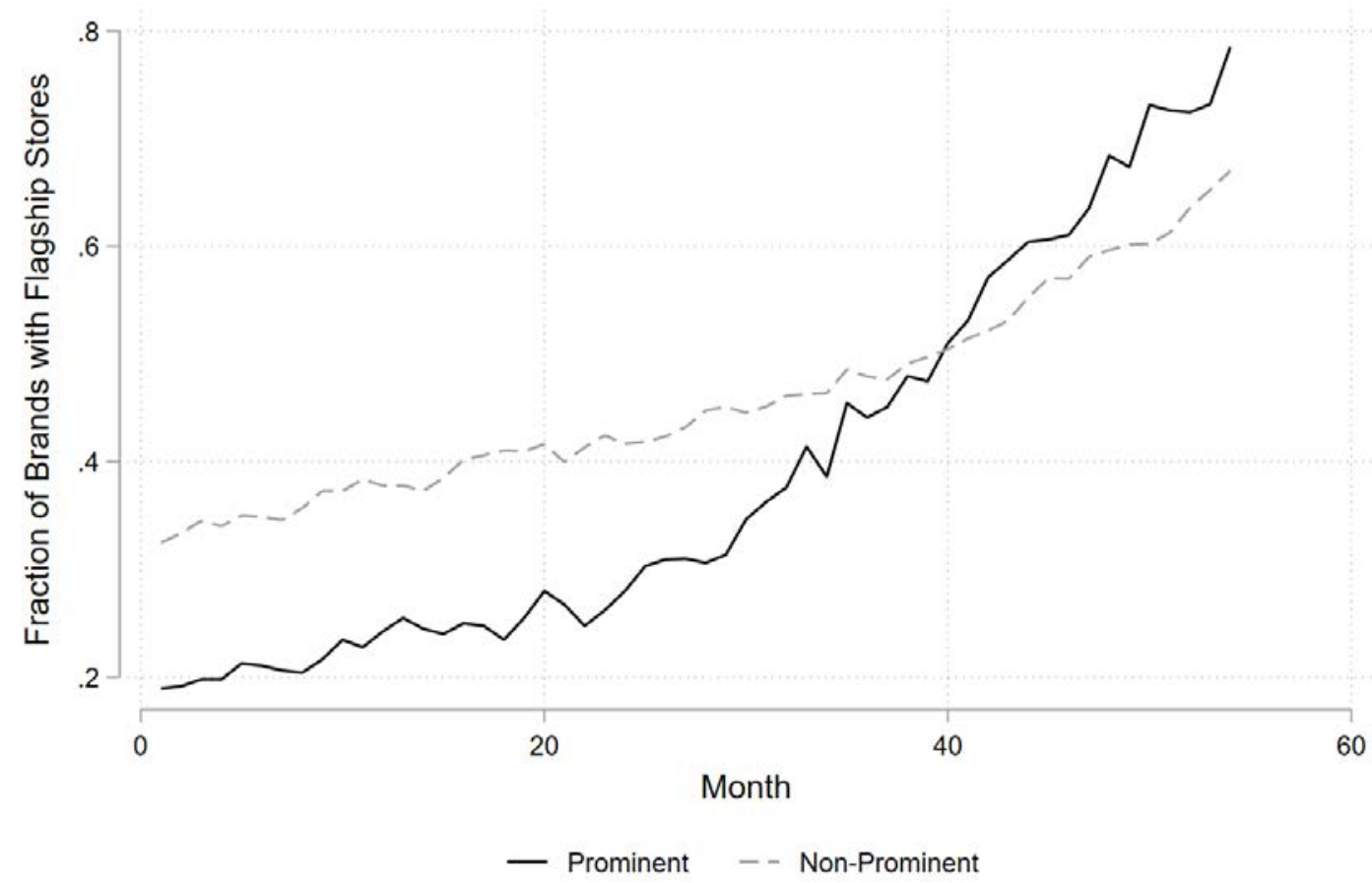

Figure 6: Nesting Structure of the Model

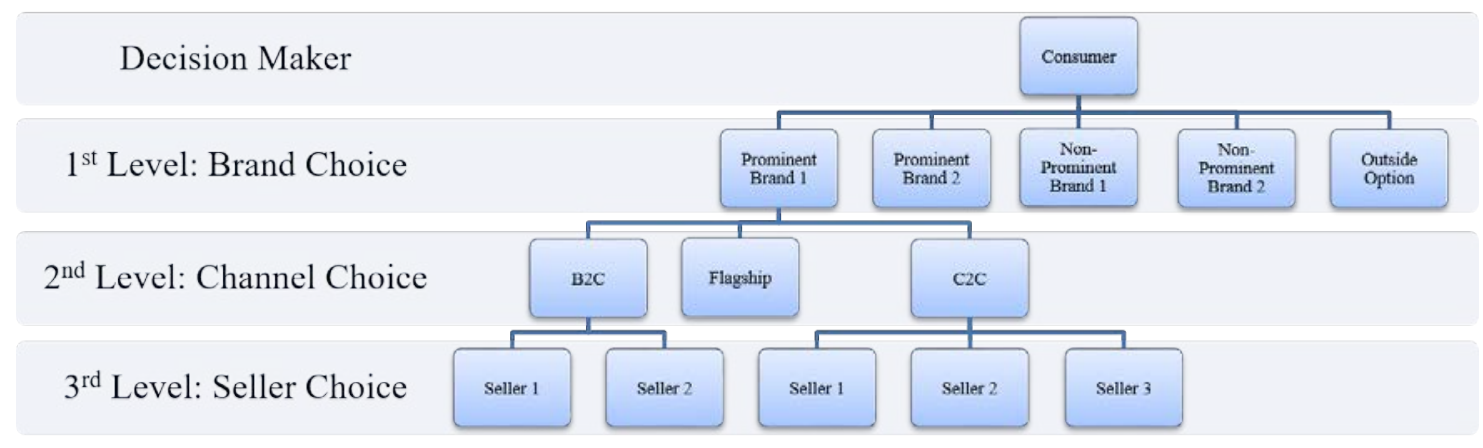


Figure 7: Estimated Product Fixed Effects (at brand-seller-year level)

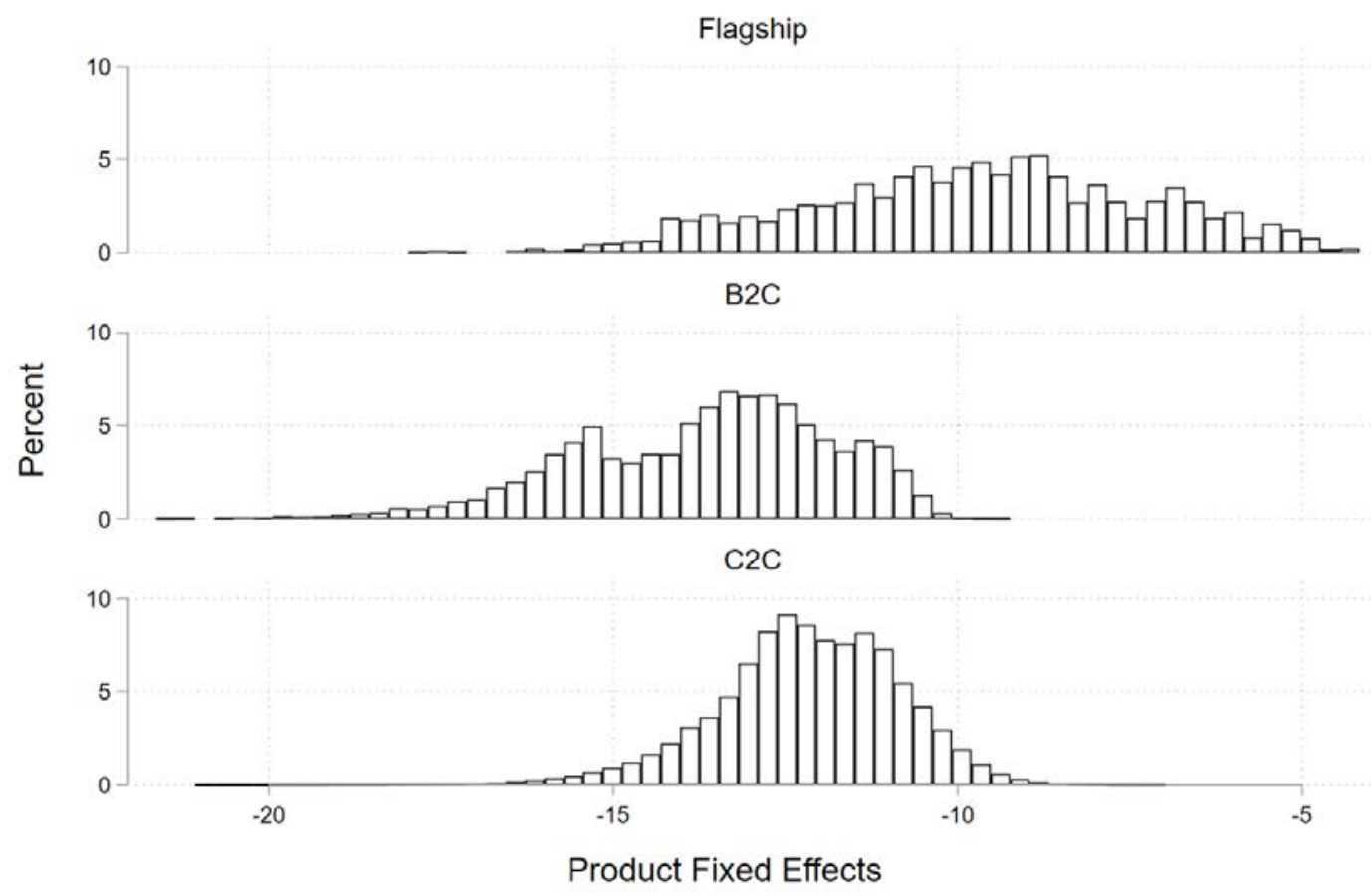

(a) Panel A: Histogram of estimated product fixed effects for prominent brands

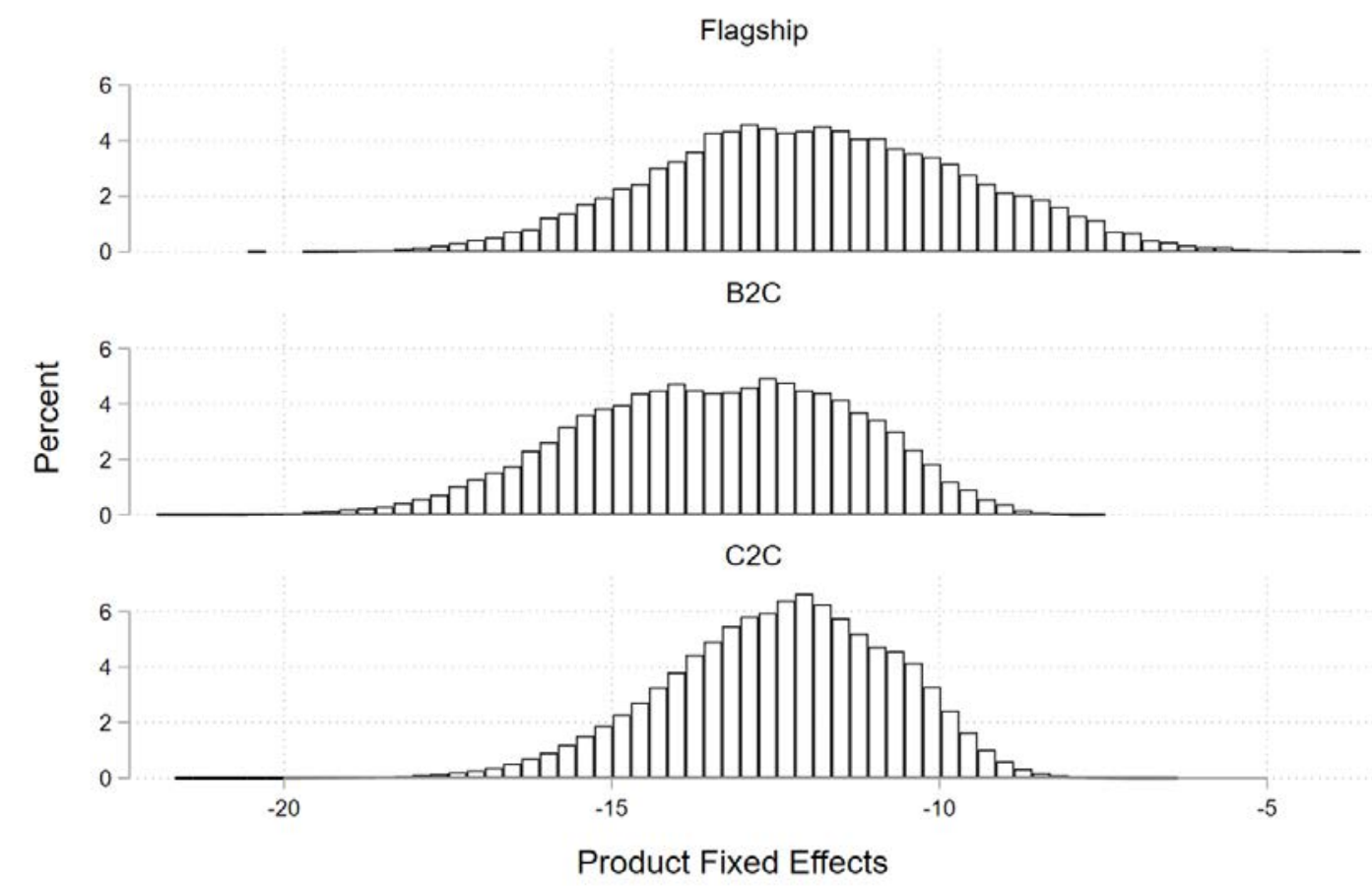

(b) Panel B: Histogram of estimated product fixed effects for non-prominent brands 
Figure 8: Price, Quantity and Estimated Elasticity: Prominent Brands

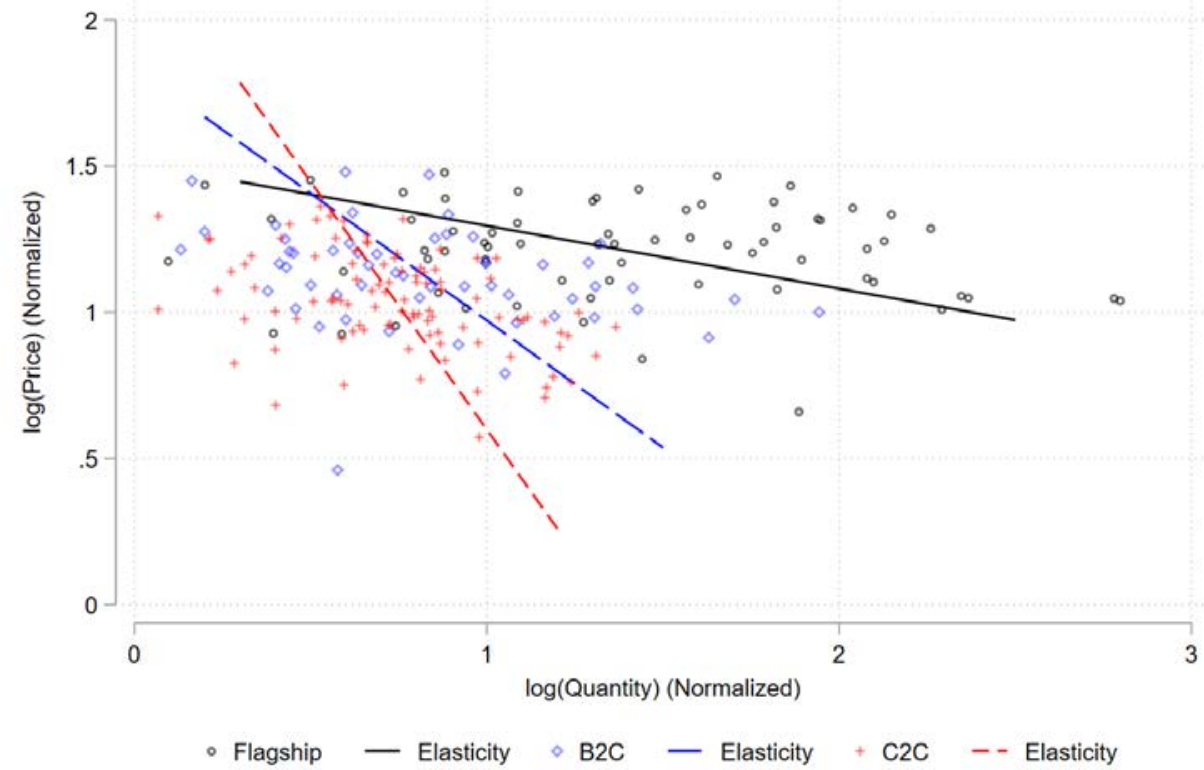

Figure 9: Price, Quantity and Estimated Elasticity: Non-Prominent Brands

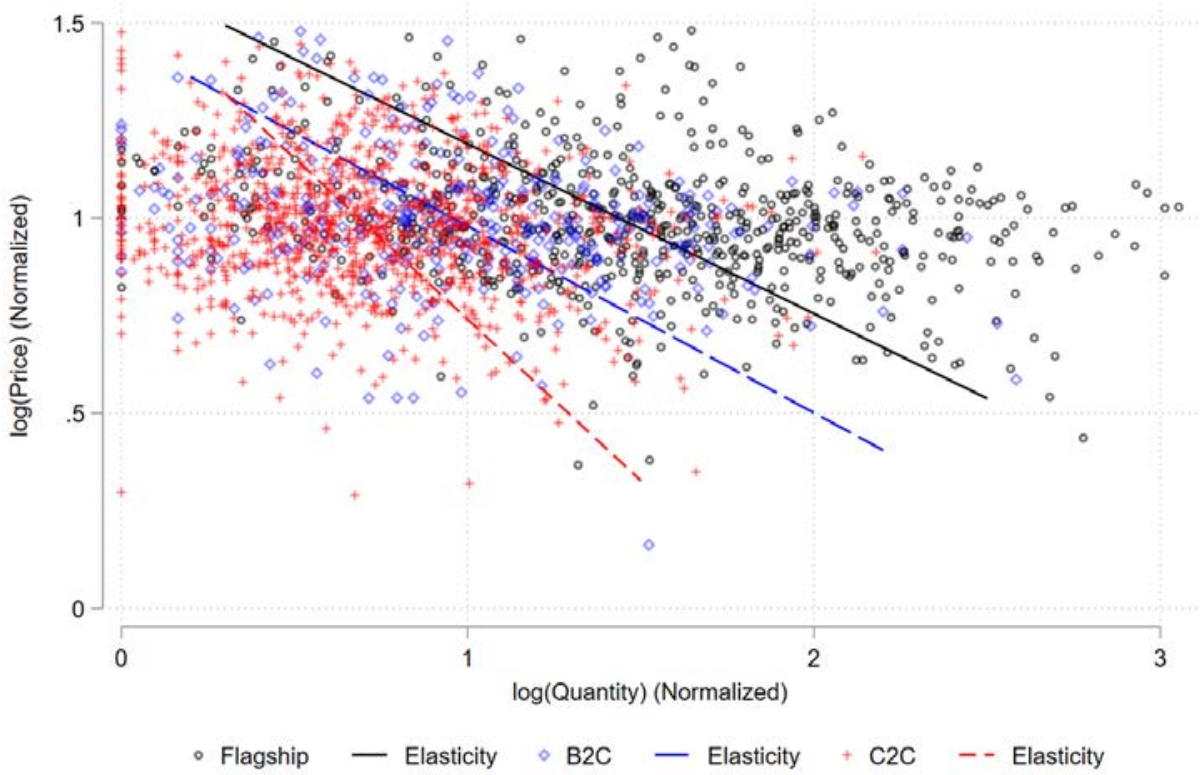


Figure 10: GMV Change: Flagship Entry of Prominent Brands

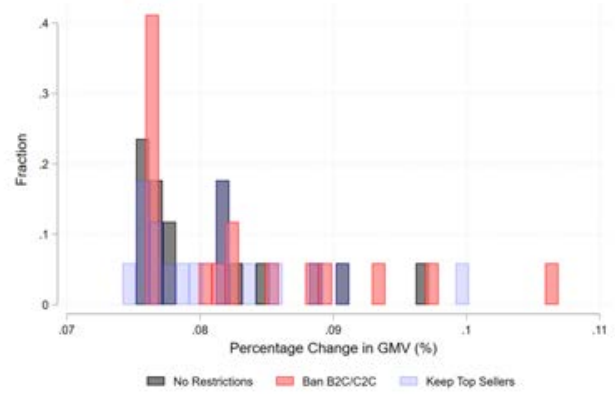

Figure 11: GMV Change: Flagship Entry of Non-Prominent Brands

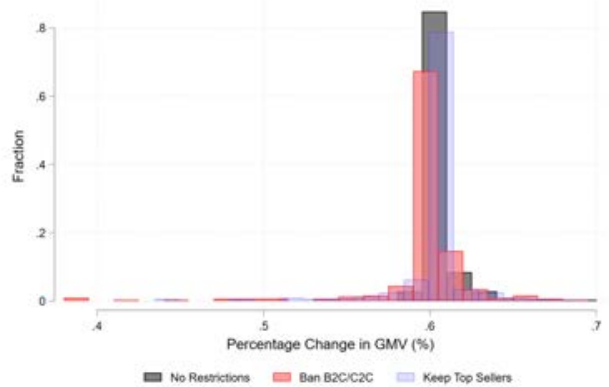

Figure 12: Consumer Welfare Change: Flagship Entry of Prominent Brands

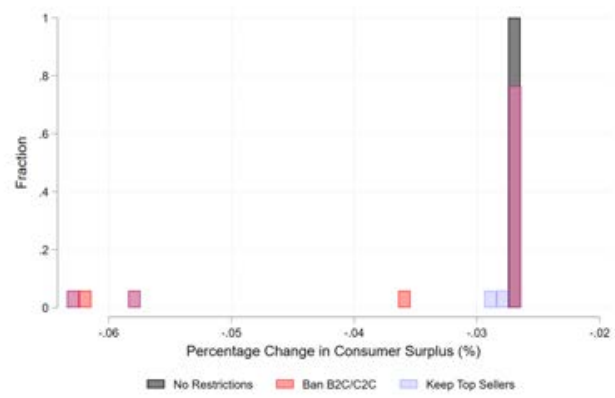

Figure 13: Consumer Welfare Change: Flagship Entry of Non-Prominent Brands

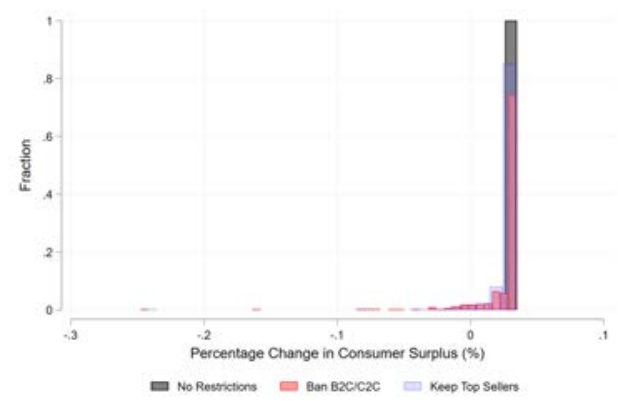




\section{Appendices}

\section{(For Online Publication)}

\section{A Robustness Checks of the Demand Model}

\section{A.1 Alternative Nesting Structures of Demand Model}

In this subsection, we try alternative specifications of the nesting structure in demand estimation. The results show that these alternative nesting structures are likely to be misspecified, which provides a robustness check to the specification in the main text.

In the first alternative specification, we switch the order of nests to "channel-then-brandthen-seller" (as opposed to the structure shown in Figure 6). The results are shown in Table 10. We can see that the estimated nesting parameters $\left(\lambda_{c}\right.$ is for the channel layer and $\lambda_{b c}$ is for the channel-brand layer) are equal or very close to 1 and sometimes even greater than 1. Since the nesting parameters have to be strictly less than 1 so that the specification is consistent with utility maximization behavior (see McFadden (1978) and McFadden (1981)), the results suggest that this nesting structure is misspecified.

Table 10: Demand Estimation Results: Alternative Nesting Structure I

\begin{tabular}{ccccccc}
\hline & & Prominent & & \multicolumn{3}{c}{ Non-Prominent } \\
& C2C & B2C & Flagship & C2C & B2C & Flagship \\
\hline$\beta_{\text {log }(\text { price })}$ & $-0.00000116^{* *}$ & 0.000000112 & -0.143 & $-0.00727^{*}$ & 0.000000122 & $-0.0866^{*}$ \\
& $(0.000000369)$ & $(0.000814)$ & $(0.0761)$ & $(0.00289)$ & $(0.0000440)$ & $(0.0383)$ \\
$\lambda_{b c}$ & $1.000^{* * *}$ & $1.000^{* * *}$ & & $0.989^{* * *}$ & $1.000^{* * *}$ & \\
& $(0.000000224)$ & $(0.000310)$ & & $(0.00455)$ & $(0.0000176)$ & \\
$\lambda_{c}$ & $1.000^{* * *}$ & $1.000^{* * *}$ & $0.963^{* * *}$ & $0.988^{* * *}$ & $1.000^{* * *}$ & $0.979^{* * *}$ \\
& $(0.000000306)$ & $(0.000356)$ & $(0.0213)$ & $(0.00449)$ & $(0.0000153)$ & $(0.0109)$ \\
FS Entry own & $-0.000000124^{*}$ & $4.05 \mathrm{e}-08$ & & $-0.000511^{*}$ & $8.82 \mathrm{e}-09$ & \\
& $(5.25 \mathrm{e}-08)$ & $(0.000997)$ & & $(0.000250)$ & $(0.0000291)$ & \\
$\rho_{1}$ & $8.168^{* * *}$ & -1.409 & $0.687^{* * *}$ & $0.714^{* * *}$ & $-0.254^{* * *}$ & $0.641^{* * *}$ \\
& $(0.00177)$ & $(0.826)$ & $(0.0629)$ & $(0.177)$ & $(0.000634)$ & $(0.115)$ \\
$\rho_{2}$ & -0.000000278 & $0.602^{* * *}$ & $0.265^{*}$ & -0.201 & $0.413^{* * *}$ & 0.0971 \\
& $(0.000000150)$ & $(0.135)$ & $(0.114)$ & $(0.188)$ & $(0.000104)$ & $(0.0929)$ \\
$\rho_{2}$ & $-7.292^{* * *}$ & $1.578^{* *}$ & 0.0361 & -0.00454 & $0.729 * * *$ & $0.267^{* * *}$ \\
& $(0.00167)$ & $(0.607)$ & $(0.0829)$ & $(0.0255)$ & $(0.000466)$ & $(0.0770)$ \\
Product FE & $\checkmark$ & $\checkmark$ & $\checkmark$ & $\checkmark$ & $\checkmark$ & $\checkmark$ \\
Year-month FE & $\checkmark$ & $\checkmark$ & $\checkmark$ & $\checkmark$ & $\checkmark$ & $\checkmark$ \\
\hline No. of Obs. & 120,681 & 2,936 & 991 & 277,845 & 16,539 & 9,662 \\
\hline
\end{tabular}

Note: We implement the same estimation strategy (based on the same sample) as that in Table 3. Clusterrobust (clustered at product level) standard errors are in parentheses. 
We also would like to explore if adding additional layers of nests could improve the performance of the model. Based on the nesting structure shown in Figure 6, we add one layer, "prominent brand or not", before the first level brand choice. The results of this specification is shown in Table 11. Note that we have an additional nesting parameter $\lambda_{b t}$ for to capture the correlation between the preference of products within a brand type (prominent or non-prominent). Again, the results show that the estimated nesting parameters are on the boundary of violating utility maximization assumption and thus suggest that the model is misspecified. Finally, we tried adding another layer (in addition to the brand type layer): inside good vs outside option; the results are similar to Table 11 and thus omitted.

Table 11: Demand Estimation Results: Alternative Nesting Structure II

\begin{tabular}{ccccccc}
\hline & & Prominent & & \multicolumn{3}{c}{ Non-Prominent } \\
Parameter & C2C & B2C & Flagship & C2C & B2C & Flagship \\
\hline$\beta_{\text {log }(\text { price })}$ & $-0.343^{* * *}$ & $2.36 \mathrm{e}-08$ & -0.120 & $-2.17 \mathrm{e}-08$ & 0.000000115 & $-0.0689^{*}$ \\
& $(0.0249)$ & $(8.75 \mathrm{e}-08)$ & $(0.0631)$ & $(4.16 \mathrm{e}-08)$ & $(0.00186)$ & $(0.0306)$ \\
$\lambda_{b c}$ & $1.180^{* * *}$ & $1.000^{* * *}$ & & $1.000^{* * *}$ & $1.000^{* * *}$ & \\
& $(0.00967)$ & $(3.22 \mathrm{e}-08)$ & & $(1.50 \mathrm{e}-08)$ & $(0.000745)$ & \\
$\lambda_{b}$ & $1.368^{* * *}$ & $1.000^{* * *}$ & $0.974^{* * *}$ & $1.000^{* * *}$ & $1.000^{* * *}$ & $0.993^{* * *}$ \\
& $(0.0185)$ & $(3.58 \mathrm{e}-08)$ & $(0.0152)$ & $(2.33 \mathrm{e}-08)$ & $(0.000625)$ & $(0.00669)$ \\
$\lambda_{b t}$ & $1.402^{* * *}$ & $1.000^{* * *}$ & $0.953^{* * *}$ & $1.000^{* * *}$ & $1.000^{* * *}$ & $0.977^{* * *}$ \\
& $(0.0171)$ & $(6.41 \mathrm{e}-08)$ & $(0.0262)$ & $(1.98 \mathrm{e}-08)$ & $(0.000865)$ & $(0.0111)$ \\
FS Entry ${ }_{\text {own }}$ & $0.0322^{* * *}$ & $-1.22 \mathrm{e}-08$ & & $2.72 \mathrm{e}-08^{* * *}$ & $3.73 \mathrm{e}-08$ & \\
& $(0.00292)$ & $(3.44 \mathrm{e}-08)$ & & $(3.71 \mathrm{e}-09)$ & $(0.00119)$ & \\
$\rho_{1}$ & $-0.365^{* * *}$ & $5.76 \mathrm{e}-08$ & $0.687^{* * *}$ & $0.984^{* * *}$ & $-3.95 \mathrm{e}-08$ & $0.634^{* * *}$ \\
& $(0.0205)$ & $(6.20 \mathrm{e}-08)$ & $(0.0630)$ & $(1.89 \mathrm{e}-08)$ & $(0.000642)$ & $(0.116)$ \\
$\rho_{2}$ & $-1.532^{* * *}$ & $-2.78 \mathrm{e}-08$ & $0.265^{*}$ & $1.10 \mathrm{e}-08$ & $-1.825^{* * *}$ & 0.0986 \\
& $(0.0146)$ & $(6.84 \mathrm{e}-08)$ & $(0.114)$ & $(1.18 \mathrm{e}-08)$ & $(0.268)$ & $(0.0948)$ \\
$\rho_{2}$ & $6.013^{* * *}$ & $0.935^{* * *}$ & 0.0356 & $-5.06 \mathrm{e}-08^{* * *}$ & $2.262^{* * *}$ & $0.273^{* * *}$ \\
& $(0.0324)$ & $(7.92 \mathrm{e}-08)$ & $(0.0825)$ & $(8.71 \mathrm{e}-09)$ & $(0.212)$ & $(0.0771)$ \\
Product FE & $\checkmark$ & $\checkmark$ & $\checkmark$ & $\checkmark$ & $\checkmark$ & $\checkmark$ \\
Year-month FE & $\checkmark$ & $\checkmark$ & $\checkmark$ & $\checkmark$ & $\checkmark$ & $\checkmark$ \\
\hline No. of Obs. & 120,681 & 2936 & 991 & 277,845 & 16,539 & 9,662 \\
\hline Not We & & & & & \\
\hline
\end{tabular}

Note: We implement the same estimation strategy (based on the same sample) as that in Table 3. Cluster-robust (clustered at product level) standard errors are in parentheses.

\section{A.2 Treating Price as Exogenous}

In this subsection, we show the results of demand estimation by treating price (and their lags) as exogenous variables. The model specification is identical to the one in Table 3 in the main text and the difference is that we do not use IV for price variables. 
Table 12: Demand Estimation Results: Treating Price as Exogenous

\begin{tabular}{ccccccc}
\hline & \multicolumn{3}{c}{ Prominent } & \multicolumn{3}{c}{ Non-Prominent } \\
& $\mathrm{C} 2 \mathrm{C}$ & $\mathrm{B} 2 \mathrm{C}$ & Flagship & $\mathrm{C} 2 \mathrm{C}$ & B2C & Flagship \\
\hline$\beta_{\text {log }(\text { price })}$ & $-0.271^{* * *}$ & $-0.154^{* * *}$ & $-0.929^{* * *}$ & $-0.354^{* * *}$ & $-0.386^{* * *}$ & $-1.087^{* * *}$ \\
& $(0.0108)$ & $(0.0396)$ & $(0.156)$ & $(0.0112)$ & $(0.0346)$ & $(0.0668)$ \\
$\lambda_{b c}$ & $0.625^{* * *}$ & $0.881^{* * *}$ & & $0.572^{* * *}$ & $0.779^{* * *}$ & \\
& $(0.0138)$ & $(0.0182)$ & & $(0.0136)$ & $(0.0306)$ & \\
$\lambda_{b}$ & $0.0947^{* * *}$ & $0.696^{* * *}$ & $0.878^{* * *}$ & $0.106^{* * *}$ & $0.659^{* * *}$ & $0.636^{* * *}$ \\
& $(0.0111)$ & $(0.0189)$ & $(0.0398)$ & $(0.0106)$ & $(0.0344)$ & $(0.0600)$ \\
FS Entry $_{\text {own }}$ & $-0.0168^{* * *}$ & -0.00771 & & $-0.0590^{* * *}$ & $0.0374^{* *}$ & \\
& $(0.00372)$ & $(0.0179)$ & & $(0.00317)$ & $(0.0158)$ & \\
$\rho_{1}$ & $0.920^{* * *}$ & $0.616^{* * *}$ & $0.648^{* * *}$ & $0.769^{* * *}$ & $0.717^{* * *}$ & $0.717^{* * *}$ \\
& $(0.0107)$ & $(0.0247)$ & $(0.0371)$ & $(0.00582)$ & $(0.0150)$ & $(0.0204)$ \\
$\rho_{2}$ & $0.0384^{* * *}$ & $0.362^{* * *}$ & $0.251^{* * *}$ & $0.154^{* * *}$ & $0.165^{* * *}$ & $0.178^{* * *}$ \\
& $(0.0142)$ & $(0.0361)$ & $(0.0599)$ & $(0.00672)$ & $(0.0220)$ & $(0.0230)$ \\
$\rho_{2}$ & $-0.0454^{* * *}$ & 0.00586 & $0.0965^{*}$ & $-0.0199^{* * *}$ & $0.0805^{* * *}$ & $0.0970^{* * *}$ \\
& $(0.00816)$ & $(0.0290)$ & $(0.0560)$ & $(0.00408)$ & $(0.0173)$ & $(0.0188)$ \\
Product FE & $\checkmark$ & $\checkmark$ & $\checkmark$ & $\checkmark$ & $\checkmark$ & $\checkmark$ \\
Year-month FE & $\checkmark$ & $\checkmark$ & $\checkmark$ & $\checkmark$ & $\checkmark$ & $\checkmark$ \\
\hline No. of Obs. & 120,681 & 2,936 & 991 & 277,845 & 16,539 & 9,662 \\
\hline
\end{tabular}

Note: We implement the classic Arellano and Bond (1991)'s first-difference GMM estimator to estimate equation (3) separately for each subsample defined by channel and whether a brand is prominent or not. Within-group shares (and their lags) are treated as endogenous variables. Robust standard errors are in parentheses, $* \mathrm{p}<0.10,{ }^{* *} \mathrm{p}<0.05,{ }^{* * *} \mathrm{p}<0.01$. 


\section{A.3 Including "Niche" Products in Demand Estimation}

Table 13: Demand Estimation Results: Including "Niche" Products

\begin{tabular}{ccccccc}
\hline \multirow{2}{*}{ Parameter } & \multicolumn{3}{c}{ Prominent } & \multicolumn{3}{c}{ Non-Prominent } \\
\cline { 2 - 7 }$\beta_{\text {log }(\text { price })}$ & $-0.0602^{* * *}$ & $-0.107^{* * *}$ & $-0.799^{* * *}$ & $-0.196^{* * *}$ & $-0.374^{* * *}$ & $-1.001^{* * *}$ \\
& $(0.0125)$ & $(0.0313)$ & $(0.148)$ & $(0.0273)$ & $(0.0529)$ & $(0.104)$ \\
$\lambda_{b c}$ & $0.880^{* * *}$ & $0.933^{* * *}$ & & $0.869^{* * *}$ & $0.834^{* * *}$ & \\
& $(0.00694)$ & $(0.0119)$ & & $(0.00993)$ & $(0.0185)$ & \\
$\lambda_{b}$ & $0.139^{* * *}$ & $0.703^{* * *}$ & $0.874^{* * *}$ & $0.238^{* * *}$ & $0.712^{* * *}$ & $0.733^{* * *}$ \\
& $(0.0262)$ & $(0.0135)$ & $(0.0336)$ & $(0.0198)$ & $(0.0186)$ & $(0.0410)$ \\
FS Entry ${ }_{\text {own }}$ & $-0.0284^{* * *}$ & $-0.0297^{* *}$ & & $-0.0467^{* * *}$ & $0.0250^{*}$ & \\
& $(0.00453)$ & $(0.0119)$ & & $(0.00571)$ & $(0.0149)$ & \\
$\rho_{1}$ & $0.927^{* * *}$ & $0.600^{* * *}$ & $0.587^{* * *}$ & $0.806^{* * *}$ & $0.720^{* * *}$ & $0.720^{* * *}$ \\
& $(0.0102)$ & $(0.0168)$ & $(0.0424)$ & $(0.00914)$ & $(0.0118)$ & $(0.0159)$ \\
$\rho_{2}$ & $0.0485^{* * *}$ & $0.389^{* * *}$ & $0.274^{* * *}$ & $0.167^{* * *}$ & $0.156^{* * *}$ & $0.170^{* * *}$ \\
& $(0.0122)$ & $(0.0249)$ & $(0.0503)$ & $(0.0105)$ & $(0.0147)$ & $(0.0203)$ \\
$\rho_{2}$ & $-0.0191^{* *}$ & -0.00722 & $0.120^{* *}$ & 0.00757 & $0.101^{* * *}$ & $0.103^{* * *}$ \\
& $(0.00961)$ & $(0.0218)$ & $(0.0521)$ & $(0.00722)$ & $(0.0125)$ & $(0.0151)$ \\
Product FE & $\checkmark$ & $\checkmark$ & $\checkmark$ & $\checkmark$ & $\checkmark$ & $\checkmark$ \\
Year-month FE & $\checkmark$ & $\checkmark$ & $\checkmark$ & $\checkmark$ & $\checkmark$ & $\checkmark$ \\
\hline No. of Obs. & 50,572 & 5,727 & 1,295 & 100,029 & 30,499 & 14,890 \\
\hline
\end{tabular}

Note: We implement the same estimation strategy (based on the same sample) as that in Table 3. But we do not drop "niche" products here. The $\mathrm{C} 2 \mathrm{C}$ results are based on a $10 \%$ sample of products instead of the full sample due to the formidable computational burden. 


\section{A.4 Removing the Data of Annual Shopping Festival}

Table 14: Demand Estimation Results: Removing the Data of Annual Shopping Festival

\begin{tabular}{ccccccc}
\hline \multirow{3}{*}{ Parameter } & \multicolumn{3}{c}{ Prominent } & \multicolumn{3}{c}{ Non-Prominent } \\
\cline { 2 - 7 }$\beta_{\text {log }(\text { price })}$ & $-0.202^{* * *}$ & $-0.112^{* *}$ & $-0.773^{* * *}$ & $-0.479^{* * *}$ & $-0.463^{* * *}$ & $-1.176^{* * *}$ \\
& $(0.0199)$ & $(0.0503)$ & $(0.159)$ & $(0.0371)$ & $(0.0638)$ & $(0.110)$ \\
$\lambda_{b c}$ & $0.669^{* * *}$ & $0.896^{* * *}$ & & $0.596^{* * *}$ & $0.806^{* * *}$ & \\
& $(0.0121)$ & $(0.0165)$ & & $(0.0138)$ & $(0.0253)$ & \\
$\lambda_{b}$ & $0.116^{* * *}$ & $0.702^{* * *}$ & $0.888^{* * *}$ & $0.108^{* * *}$ & $0.671^{* * *}$ & $0.717^{* * *}$ \\
& $(0.0105)$ & $(0.0189)$ & $(0.0371)$ & $(0.0110)$ & $(0.0331)$ & $(0.0530)$ \\
FS Entry ${ }_{\text {own }}$ & $-0.0228^{* * *}$ & -0.0251 & & $-0.0692^{* * *}$ & 0.0100 & \\
& $(0.00357)$ & $(0.0183)$ & & $(0.00345)$ & $(0.0161)$ & \\
$\rho_{1}$ & $0.923^{* * *}$ & $0.614^{* * *}$ & $0.641^{* * *}$ & $0.777^{* * *}$ & $0.714^{* * *}$ & $0.712^{* * *}$ \\
& $(0.0110)$ & $(0.0244)$ & $(0.0365)$ & $(0.00581)$ & $(0.0149)$ & $(0.0195)$ \\
$\rho_{2}$ & $0.0384^{* *}$ & $0.362^{* * *}$ & $0.258^{* * *}$ & $0.152^{* * *}$ & $0.165^{* * *}$ & $0.178^{* * *}$ \\
& $(0.0150)$ & $(0.0363)$ & $(0.0588)$ & $(0.00664)$ & $(0.0225)$ & $(0.0222)$ \\
$\rho_{2}$ & $-0.0464^{* * *}$ & 0.00958 & $0.0947^{*}$ & $-0.0215^{* * *}$ & $0.0818^{* * *}$ & $0.0932^{* * *}$ \\
& $(0.00849)$ & $(0.0293)$ & $(0.0544)$ & $(0.00406)$ & $(0.0173)$ & $(0.0174)$ \\
Product FE & $\checkmark$ & $\checkmark$ & $\checkmark$ & $\checkmark$ & $\checkmark$ & $\checkmark$ \\
Year-month FE & $\checkmark$ & $\checkmark$ & $\checkmark$ & $\checkmark$ & $\checkmark$ & $\checkmark$ \\
\hline No. of Obs. & 107,928 & 2,632 & 890 & 249,250 & 14,829 & 8,660 \\
\hline
\end{tabular}

Note: We implement the same estimation strategy as that in Table 3. But we drop the data on November's to remove the potential effects of the annual shopping festival on our estimates. 


\section{A.5 Imposing Common Nesting Parameters Across Different Brand Types and Channels}

Table 15: Demand Estimation Results: Imposing Common Nesting Parameters

\begin{tabular}{|c|c|c|c|c|c|c|}
\hline \multirow[b]{2}{*}{ Parameter } & \multicolumn{3}{|c|}{ Prominent } & \multicolumn{3}{|c|}{ Non-Prominent } \\
\hline & $\mathrm{C} 2 \mathrm{C}$ & $\mathrm{B} 2 \mathrm{C}$ & Flagship & $\mathrm{C} 2 \mathrm{C}$ & $\mathrm{B} 2 \mathrm{C}$ & Flagship \\
\hline$\beta_{\log (\text { price })}$ & $-0.0459^{*}$ & $\begin{array}{c}-0.473^{* * *} \\
(0.114)\end{array}$ & $-1.640^{* * *}$ & $-0.141^{* * *}$ & $-0.522^{* * *}$ & $-1.084^{* * *}$ \\
\hline$\lambda_{b c}$ & \multicolumn{2}{|c|}{$\begin{array}{c}0.895^{* * *} \\
(0.0138)\end{array}$} & (0.00) & \multicolumn{2}{|c|}{$\begin{array}{r}0.895^{* * *} \\
(0.0138)\end{array}$} & ) \\
\hline$\lambda_{b}$ & \multicolumn{6}{|c|}{$\begin{array}{l}0.575^{* * *} \\
(0.0341)\end{array}$} \\
\hline FS Entry & $\begin{array}{c}-0.0471^{* *} \\
(0.0198)\end{array}$ & $\begin{array}{l}0.00805 \\
(0.0367)\end{array}$ & - & $\begin{array}{c}-0.0308^{* * *} \\
(0.00811)\end{array}$ & $\begin{array}{c}-0.000807 \\
(0.0616)\end{array}$ & - \\
\hline$\rho_{1}$ & $\begin{array}{c}0.834^{* * *} \\
(0.0138)\end{array}$ & $\begin{array}{c}0.707^{* * *} \\
(0.0281)\end{array}$ & $\begin{array}{l}0.578^{* * *} \\
(0.0506)\end{array}$ & $\begin{array}{c}0.835^{* * *} \\
(0.0139)\end{array}$ & $\begin{array}{c}0.757^{* * *} \\
(0.0232)\end{array}$ & $\begin{array}{c}0.641 * * * \\
(0.0336)\end{array}$ \\
\hline$\rho_{2}$ & $\begin{array}{c}0.126^{* * *} \\
(0.0189)\end{array}$ & $\begin{array}{c}0.251^{* * *} \\
(0.0315)\end{array}$ & $\begin{array}{c}0.161^{* * *} \\
(0.0488)\end{array}$ & $\begin{array}{c}0.128^{* * *} \\
(0.0196)\end{array}$ & $\begin{array}{c}0.163^{* * *} \\
(0.0252)\end{array}$ & $\begin{array}{c}0.281^{* * *} \\
(0.0309)\end{array}$ \\
\hline$\rho_{2}$ & $\begin{array}{l}0.00415 \\
(0.0108)\end{array}$ & $\begin{array}{l}0.00132 \\
(0.0232)\end{array}$ & $\begin{array}{c}0.255^{* * *} \\
(0.0532)\end{array}$ & $\begin{array}{r}-0.00916 \\
(0.0111)\end{array}$ & $\begin{array}{c}0.0451^{* *} \\
(0.0216)\end{array}$ & $\begin{array}{c}0.0229 \\
(0.0305)\end{array}$ \\
\hline $\begin{array}{l}\text { Product FE } \\
\text { Year-month FE }\end{array}$ & \multicolumn{6}{|c|}{$\checkmark$} \\
\hline No. of Obs. & \multicolumn{6}{|c|}{428,654} \\
\hline
\end{tabular}

Note: We implement the the same estimator as that in Table 3, but with pooled data and imposed common nesting parameters across different brand types/channels. Also, the estimation is based on a $10 \%$ random sample of products to make the computation feasible.

\section{A.6 Adding Random Coefficients on (log) Price}

We extend the baseline demand model in the main text to include normally distributed random coefficients (brand type and channel specific) on log price. To estimate the extended model, we use the two-step estimator proposed by Lu et al. (2022) (with a parametric specification for the second-step); the market shares are computed based on 1000 simulation draws. The results are shown in Table 16. Results suggest that only the "ProminentFlagship" group has a statistically significant (estimated) standard deviation of the random coefficient, and its magnitude is rather small comparing to the mean of the random coefficient. Based on these results, we conclude that incorporating preference heterogeneity on price has a small impact on our baseline demand and supply results in the main text. 
Table 16: Demand Estimation Results: Random Coefficients on Price

\begin{tabular}{ccccccc}
\hline & \multicolumn{3}{c}{ Prominent } & \multicolumn{3}{c}{ Non-Prominent } \\
\cline { 2 - 7 } & C2C & B2C & Flagship & C2C & B2C & Flagship \\
\hline Nean & $-0.102^{* * *}$ & $-0.124^{* *}$ & $-1.3630^{* * *}$ & $-0.1697^{* * *}$ & $-0.3922^{* * *}$ & $-.9341^{* * *}$ \\
& $(0.0006)$ & $(0.0016)$ & $(0.0249)$ & $(0.0003)$ & $(0.0008)$ & $(0.0038)$ \\
S.D. & .000 & .000 & $.3326^{* * *}$ & .000 & .000 & .000 \\
& $(.0187)$ & $(.0500)$ & $(.0122)$ & $(.0086)$ & $(.0233)$ & $(.1179)$ \\
\hline \multicolumn{7}{c}{ Non-Random Fixed Coefficients } \\
\hline$\lambda_{b c}$ & $0.734^{* * *}$ & $0.897^{* * *}$ & \multicolumn{5}{c}{$0.673^{* * *}$} & $0.799^{* * *}$ \\
& $(0.0121)$ & $(0.0163)$ & $(0.0118)$ & $(0.0261)$ & \\
$\lambda_{b}$ & $0.0832^{* * *}$ & $0.679^{* * *}$ & $0.911^{* * *}$ & $0.109^{* * *}$ & $0.647^{* * *}$ & $0.685^{* * *}$ \\
& $(0.00922)$ & $(0.0204)$ & $(0.0313)$ & $(0.0104)$ & $(0.0322)$ & $(0.0506)$ \\
FS Entry & $-0.0192^{* * *}$ & -0.0215 & \multicolumn{5}{c}{$-0.0596^{* * *}$} & $0.0282^{*}$ & \\
& $(0.00418)$ & $(0.0184)$ & $(0.00365)$ & $(0.0149)$ & \\
$\rho_{1}$ & $0.922^{* * *}$ & $0.624^{* * *}$ & $0.657^{* * *}$ & $0.783^{* * *}$ & $0.735^{* * *}$ & $0.722^{* * *}$ \\
& $(0.0113)$ & $(0.0246)$ & $(0.0350)$ & $(0.00570)$ & $(0.0154)$ & $(0.0194)$ \\
$\rho_{2}$ & $0.0429^{* * *}$ & $0.360^{* * *}$ & $0.253^{* * *}$ & $0.159^{* * *}$ & $0.151^{* * *}$ & $0.171^{* * *}$ \\
& $(0.0148)$ & $(0.0361)$ & $(0.0580)$ & $(0.00669)$ & $(0.0224)$ & $(0.0227)$ \\
$\rho_{2}$ & $-0.0367^{* * *}$ & 0.00163 & 0.0821 & $-0.0209^{* * *}$ & $0.0791^{* * *}$ & $0.0967^{* * *}$ \\
& $(0.00894)$ & $(0.0285)$ & $(0.0561)$ & $(0.00402)$ & $(0.0168)$ & $(0.0169)$ \\
Product FE & $\checkmark$ & $\checkmark$ & $\checkmark$ & $\checkmark$ & $\checkmark$ & $\checkmark$ \\
Month FE & $\checkmark$ & $\checkmark$ & $\checkmark$ & $\checkmark$ & $\checkmark$ & $\checkmark$ \\
\hline No. of Obs. & 120,681 & 2,936 & 991 & 277,845 & 16,539 & 9,662 \\
\hline
\end{tabular}

Note: This table shows the results from an extension of the baseline demand model in the main text. The extension incorporates normally distributed random coefficients (brand type and channel specific) on $\log$ price. Standard errors are in parentheses, ${ }^{*} \mathrm{p}<0.10,{ }^{* *} \mathrm{p}<0.05,{ }^{* * *} \mathrm{p}<0.01$.

\section{B An Alternative Model of Flagship Stores' Conduct}

In this appendix, we assume the profit function of the flagship store of a brand incorporates the profits of the $\mathrm{B} 2 \mathrm{C} / \mathrm{C} 2 \mathrm{C}$ stores that sell the same brand (see, among others, Ciliberto and Williams (2014) and Sudhir (2001a)), as a robustness check of the specification of flagship stores' conduct (described by equation (7)) in the main text.

In particular, let the objective of a flagship store $j$ (or store-brand-year $j$ ) be

$$
\begin{aligned}
\max _{P_{j t}}\left\{\left(P_{j t}-M C_{j t}\right) Q_{j t}\left(\mathbf{P}_{t}\right)\right. \\
\left.\quad+\varphi_{B 2 C}^{\prime} \sum_{k \in \mathcal{B}_{j t}^{B C C}}\left(P_{k t}-M C_{k t}\right) Q_{k t}\left(\mathbf{P}_{t}\right)+\varphi_{C 2 C}^{\prime} \sum_{k \in \mathcal{B}_{j t}^{C L C}}\left(P_{k t}-M C_{k t}\right) Q_{k t}\left(\mathbf{P}_{t}\right)\right\},
\end{aligned}
$$


where $\mathcal{B}_{j t}^{B 2 C}$ and $\mathcal{B}_{j t}^{C 2 C}$ are the sets of products that are of the same brand as $j$ on $\mathrm{C} 2 \mathrm{C}$ and B2C Market, respectively, and $\varphi_{C 2 C}^{\prime}$ and $\varphi_{B 2 C}^{\prime}$ measure how the flagship store(brand) incorporates the profitability of $\mathrm{B} 2 \mathrm{C} / \mathrm{C} 2 \mathrm{C}$ stores selling the same brand.

Under this alternative specification of sellers' conduct, we can derive the FOCs that characterize the price equilibrium in a market. To gain some intuition on the structure of the first-order conditions, we simplify the notation by focusing on a generic brand and assume that there is only one store on each channel selling this brand. Specifically, the first-order conditions in this simple case can be written collectively as

$$
\left(\begin{array}{c}
Q^{F S} \\
Q^{B 2 C} \\
Q^{C 2 C}
\end{array}\right)+\underbrace{\left[\begin{array}{ccc}
\frac{\partial Q^{F S}}{\partial P^{F S}} & \varphi_{B 2 C}^{\prime} \frac{\partial Q^{B 2 C}}{\partial P^{F S}} & \varphi_{C 2 C}^{\prime} \frac{\partial Q^{C 2 C}}{\partial P^{F S}} \\
0 & \frac{\partial Q^{B 2 C}}{\partial P^{B 2 C}} & 0 \\
0 & 0 & \frac{\partial Q^{C 2 C}}{\partial P^{C 2 C}}
\end{array}\right]}_{\Omega}\left(\begin{array}{c}
P^{F S}-M C^{F S} \\
P^{B 2 C}-M C^{B 2 C} \\
P^{C 2 C}-M C^{C 2 C}
\end{array}\right)=0,
$$

where $\Omega$ summarizes the restrictions we have imposed on sellers' conduct on the platform.

Exploiting the structure of $\Omega$, we can invert the system (12) in close-form to obtain the markup system

$$
\left(\begin{array}{c}
P^{F S}-M C^{F S} \\
P^{B 2 C}-M C^{B 2 C} \\
P^{C 2 C}-M C^{C 2 C}
\end{array}\right)=\underbrace{\left[\begin{array}{ccc}
-\left(\frac{\partial Q^{F S}}{\partial P^{F S}}\right)^{-1} & \varphi_{B 2 C}^{\prime}\left(\frac{\partial Q^{F S}}{\partial P^{B 2 C}}\right)^{-1} & \varphi_{C 2 C}^{\prime}\left(\frac{\partial Q^{F S}}{\partial P^{C 2 C}}\right)^{-1} \\
0 & -\left(\frac{\partial Q^{B 2 C}}{\partial P^{B 2 C}}\right)^{-1} & 0 \\
0 & 0 & -\left(\frac{\partial Q^{C 2 C}}{\partial P^{C 2 C}}\right)^{-1}
\end{array}\right]}_{\Omega^{-1}}\left(\begin{array}{c}
Q^{F S} \\
Q^{B 2 C} \\
Q^{C 2 C}
\end{array}\right) .
$$

For the general case with multiple brands and also multiple sellers within a brand-channel pair, it is straightforward to generalize the above close-form inversion of $\Omega$ so that we can obtain the following markup equation for flagship stores

$$
\begin{aligned}
& P_{j t}^{F S}+\left(\frac{\partial Q_{j t}^{F S}}{\partial P_{j t}^{F S}}\right)^{-1} Q_{j t}^{F S} \\
= & M C_{j t}^{F S}+\varphi_{B 2 C}^{\prime} \sum_{k \in \mathcal{B}_{j t}^{B 2 C}}\left(\frac{\partial Q_{j t}^{F S}}{\partial P_{k t}^{B 2 C}}\right)^{-1} Q_{k t}^{B 2 C}+\varphi_{C 2 C}^{\prime} \sum_{k \in \mathcal{B}_{j t}^{C 2 C}}\left(\frac{\partial Q_{j t}^{F S}}{\partial P_{k t}^{C 2 C}}\right)^{-1} Q_{k t}^{C 2 C},
\end{aligned}
$$

where all the derivatives can be obtained from the estimated demand system.

Based on this equation, we estimated $\varphi_{B 2 C}^{\prime}$ and $\varphi_{C 2 C}^{\prime}$ using the same moment condition as in Section 4.1. The results are shown in Table 17. 
Table 17: Supply Side Estimation Results under Alternative Conduct Specification

\begin{tabular}{|c|c|c|c|c|}
\hline \multicolumn{5}{|c|}{ Conduct Parameter } \\
\hline \multirow{2}{*}{\multicolumn{3}{|c|}{$\hat{\varphi}_{B 2 C}^{\prime}$}} & Prominent & Non-Prominent \\
\hline & & & $-2.74 \mathrm{E}-7$ & $-1.49 \mathrm{E}-5$ \\
\hline \multicolumn{3}{|c|}{$\varphi_{B 2 C}$} & $(3.46 \mathrm{E}-6)$ & $(2.84 \mathrm{E}-5)$ \\
\hline \multirow{2}{*}{\multicolumn{3}{|c|}{$\hat{\varphi}_{C 2 C}^{\prime}$}} & $-4.79 \mathrm{E}-11$ & $5.27 \mathrm{E}-9$ \\
\hline & & & $(3.75 \mathrm{E}-10)$ & $(1.16 \mathrm{E}-8)$ \\
\hline \multicolumn{5}{|c|}{ Marginal Cost and Markup (Median and 5\% and 95\% Percentiles) } \\
\hline \multirow{5}{*}{ Prominent } & & Flagship & $\mathrm{B} 2 \mathrm{C}$ & $\mathrm{C} 2 \mathrm{C}$ \\
\hline & $\mathrm{MC}$ & 5.12 & .35 & -1.36 \\
\hline & (Normalized) & {$[.62,11.29]$} & {$[-5.60,1.40]$} & {$[-6.59,-.10]$} \\
\hline & & $14.85 \%$ & $81.33 \%$ & $169.71 \%$ \\
\hline & Markup & {$[13.66 \%, 70.05 \%]$} & {$[78.26 \%, 233.05 \%]$} & {$[169.70 \%, 170.55 \%]$} \\
\hline \multirow{4}{*}{ Non-Prominent } & $\mathrm{MC}$ & 1 & .86 & .29 \\
\hline & (Normalized) & {$[.14,4.08]$} & {$[.06,2.50]$} & {$[.03,1.14]$} \\
\hline & Marlouve & $36.72 \%$ & $44.08 \%$ & $82.07 \%$ \\
\hline & Markup & {$[24.74 \%, 85.92 \%]$} & {$[41.66 \%, 82.19 \%]$} & {$[82.06 \%, 84.72 \%]$} \\
\hline
\end{tabular}

Note: The MC's are normalized by the MC for the non-prominent, flagship case.

We can see that none of the estimated conduct parameters is significant, which aligns with the results in the main text, i.e., the is little evidence that a flagship store internalizes the $\mathrm{B} 2 \mathrm{C} / \mathrm{C} 2 \mathrm{C}$ sales of the same brand.

We further re-run the counterfactual simulations using this conduct specification. As expected, the results are virtually the same as the baseline conduct specification in the main text and are omitted to spare space. 


\section{The full set of counterfactual results}

Table 18: Effects of Flagship Entry: Without Direct Within-Brand or AcrossBrand Effects

\begin{tabular}{|c|c|c|c|c|c|c|}
\hline \multicolumn{7}{|c|}{ Panel A: Prominent Brands } \\
\hline \multirow{4}{*}{ Entrant } & Price (Norm & ized) & \multicolumn{4}{|c|}{2.78} \\
\hline & \multicolumn{2}{|c|}{ Ouantity (Normalized) } & \multicolumn{4}{|c|}{3.25} \\
\hline & \multicolumn{2}{|c|}{ GMV (Normalized) } & \multicolumn{4}{|c|}{3.86} \\
\hline & \multicolumn{2}{|c|}{ Profit (Normalized) } & \multicolumn{4}{|c|}{.42} \\
\hline \multirow{6}{*}{ Incumbent } & & \multicolumn{2}{|c|}{ Within Brand } & \multicolumn{3}{|c|}{ Other Brands } \\
\hline & & $\mathrm{B} 2 \mathrm{C}$ & $\mathrm{C} 2 \mathrm{C}$ & FS & $\mathrm{B} 2 \mathrm{C}$ & $\mathrm{C} 2 \mathrm{C}$ \\
\hline & $\% \Delta$ Price & $-13.24 \%$ & $-1.85 \%$ & $.001 \%$ & $.03 \%$ & $.005 \%$ \\
\hline & $\% \Delta$ Quantity & $-35.16 \%$ & $-13.87 \%$ & $-.0002 \%$ & $-.01 \%$ & $-.002 \%$ \\
\hline & $\% \Delta \mathrm{GMV}$ & $-42.88 \%$ & $-15.47 \%$ & $.0008 \%$ & $.02 \%$ & $.003 \%$ \\
\hline & $\% \Delta$ Profit & $-39.11 \%$ & $-14.73 \%$ & $.0005 \%$ & $.02 \%$ & $.002 \%$ \\
\hline \multirow{2}{*}{\multicolumn{2}{|c|}{$\begin{array}{c}\% \Delta \text { Overall Consumer Surplus } \\
\% \Delta \text { Overall GMV }\end{array}$}} & \multicolumn{5}{|c|}{$.50759 \%$} \\
\hline & & \multicolumn{5}{|c|}{$.00879 \%$} \\
\hline \multicolumn{7}{|c|}{ Panel B: Non-Prominent Brands } \\
\hline \multirow{4}{*}{ Entrant } & \multicolumn{2}{|c|}{ Price (Normalized) } & \multicolumn{4}{|c|}{1.52} \\
\hline & \multicolumn{2}{|c|}{ Quantity (Normalized) } & \multicolumn{4}{|c|}{1.25} \\
\hline & \multirow{2}{*}{\multicolumn{2}{|c|}{$\begin{array}{l}\text { GMV (Normalized) } \\
\text { Profit (Normalized) }\end{array}$}} & \multicolumn{4}{|c|}{1.35} \\
\hline & & & \multicolumn{4}{|c|}{.51} \\
\hline \multirow{6}{*}{ Incumbent } & & \multicolumn{2}{|c|}{ Within Brand } & \multicolumn{3}{|c|}{ Other Brands } \\
\hline & & $\mathrm{B} 2 \mathrm{C}$ & $\mathrm{C} 2 \mathrm{C}$ & FS & $\mathrm{B} 2 \mathrm{C}$ & $\mathrm{C} 2 \mathrm{C}$ \\
\hline & $\% \Delta$ Price & $-1.43 \%$ & $-.003 \%$ & $.001 \%$ & $.03 \%$ & $.005 \%$ \\
\hline & $\% \Delta$ Quantity & $-43.23 \%$ & $-8.15 \%$ & $-.0002 \%$ & $-.01 \%$ & $-.002 \%$ \\
\hline & $\% \Delta \mathrm{GMV}$ & $-49.65 \%$ & $-8.91 \%$ & $.0008 \%$ & $.02 \%$ & $.003 \%$ \\
\hline & $\% \Delta$ Profit & $-49.90 \%$ & $-9.05 \%$ & $.0005 \%$ & $.02 \%$ & $.002 \%$ \\
\hline \multirow{2}{*}{\multicolumn{2}{|c|}{$\begin{array}{c}\% \Delta \text { Overall Consumer Surplus } \\
\% \Delta \text { Overall GMV }\end{array}$}} & \multicolumn{5}{|c|}{$.50759 \%$} \\
\hline & & & & $00754 \%$ & & \\
\hline
\end{tabular}

Note: For each brand (that does not have flagship store), we simulate the entry of its flagship store and summarize the outcome. For the entering flagship store, the outcome variables are normalized by those of the within-brand incumbent sellers. For the incumbent sellers, we calculate the GMV-weighted average of percent changes of the outcome variables. Finally, the numbers reported in this table are the averages across these brands. 
Table 19: Effects of Flagship Entry: Without Direct Across-Brand Effects

\begin{tabular}{|c|c|c|c|c|c|c|}
\hline \multicolumn{7}{|c|}{ Panel A: Prominent Brands } \\
\hline \multirow{4}{*}{ Entrant } & \multirow{2}{*}{\multicolumn{2}{|c|}{$\begin{array}{l}\text { Price (Normalized) } \\
\text { Ouantity (Normalized) }\end{array}$}} & \multicolumn{4}{|c|}{2.79} \\
\hline & & & \multicolumn{4}{|c|}{3.24} \\
\hline & \multicolumn{2}{|c|}{ GMV (Normalized) } & \multicolumn{4}{|c|}{3.90} \\
\hline & \multicolumn{2}{|c|}{ Profit (Normalized) } & \multicolumn{4}{|c|}{.43} \\
\hline \multirow{6}{*}{ Incumbent } & & \multicolumn{2}{|c|}{ Within Brand } & \multicolumn{3}{|c|}{ Other Brands } \\
\hline & & B2C & $\mathrm{C} 2 \mathrm{C}$ & FS & $\mathrm{B} 2 \mathrm{C}$ & $\mathrm{C} 2 \mathrm{C}$ \\
\hline & $\% \Delta$ Price & $-13.24 \%$ & $-1.85 \%$ & $.001 \%$ & $.03 \%$ & $.005 \%$ \\
\hline & $\% \Delta$ Quantity & $-33.91 \%$ & $-15.65 \%$ & $-.0002 \%$ & $.01 \%$ & $-.002 \%$ \\
\hline & $\% \Delta \mathrm{GMV}$ & $-41.78 \%$ & $-17.22 \%$ & $.0008 \%$ & $.02 \%$ & $.003 \%$ \\
\hline & $\% \Delta$ Profit & $-37.93 \%$ & $-16.49 \%$ & $.0005 \%$ & $.02 \%$ & $.002 \%$ \\
\hline \multirow{2}{*}{\multicolumn{2}{|c|}{$\begin{array}{c}\% \Delta \text { Overall Consumer Surplus } \\
\% \Delta \text { Overall GMV }\end{array}$}} & \multicolumn{5}{|c|}{$-.000168 \%$} \\
\hline & & \multicolumn{5}{|c|}{$.00883 \%$} \\
\hline \multicolumn{7}{|c|}{ Panel B: Non-Prominent Brands } \\
\hline \multirow{4}{*}{ Entrant } & Price (Norm & ized) & \multicolumn{4}{|c|}{1.55} \\
\hline & \multicolumn{2}{|c|}{ Quantity (Normalized) } & \multicolumn{4}{|c|}{1.25} \\
\hline & \multirow{2}{*}{\multicolumn{2}{|c|}{$\begin{array}{l}\text { GMV (Normalized) } \\
\text { Profit (Normalized) }\end{array}$}} & \multicolumn{4}{|c|}{1.39} \\
\hline & & & \multicolumn{4}{|c|}{.52} \\
\hline \multirow{6}{*}{ Incumbent } & & \multicolumn{2}{|c|}{ Within Brand } & \multicolumn{3}{|c|}{ Other Brands } \\
\hline & & $\mathrm{B} 2 \mathrm{C}$ & $\mathrm{C} 2 \mathrm{C}$ & FS & $\mathrm{B} 2 \mathrm{C}$ & $\mathrm{C} 2 \mathrm{C}$ \\
\hline & $\% \Delta$ Price & $-.63 \%$ & $-.01 \%$ & $.001 \%$ & $.03 \%$ & $.005 \%$ \\
\hline & $\% \Delta$ Quantity & $-34.24 \%$ & $-14.93 \%$ & $-.0002 \%$ & $-.01 \%$ & $-.002 \%$ \\
\hline & $\% \Delta \mathrm{GMV}$ & $-41.41 \%$ & $-15.66 \%$ & $.0008 \%$ & $.02 \%$ & $.003 \%$ \\
\hline & $\% \Delta$ Profit & $-44.29 \%$ & $-15.93 \%$ & $.0005 \%$ & $.02 \%$ & $.002 \%$ \\
\hline $\begin{array}{r}\% \Delta \text { Overall } \\
\% \Delta \mathrm{O}\end{array}$ & $\begin{array}{l}\text { nsumer Surplus } \\
\text { all GMV }\end{array}$ & & & $\begin{array}{l}00173 \% \\
0648 \%\end{array}$ & & \\
\hline
\end{tabular}

Note: For each brand (that does not have flagship store), we simulate the entry of its flagship store and summarize the outcome. For the entering flagship store, the outcome variables are normalized by those of the within-brand incumbent sellers. For the incumbent sellers, we calculate the GMV-weighted average of percent changes of the outcome variables. Finally, the numbers reported in this table are the averages across these brands. 
Table 20: Effects of Flagship Entry: With Restrictions on Third-Party Sellers

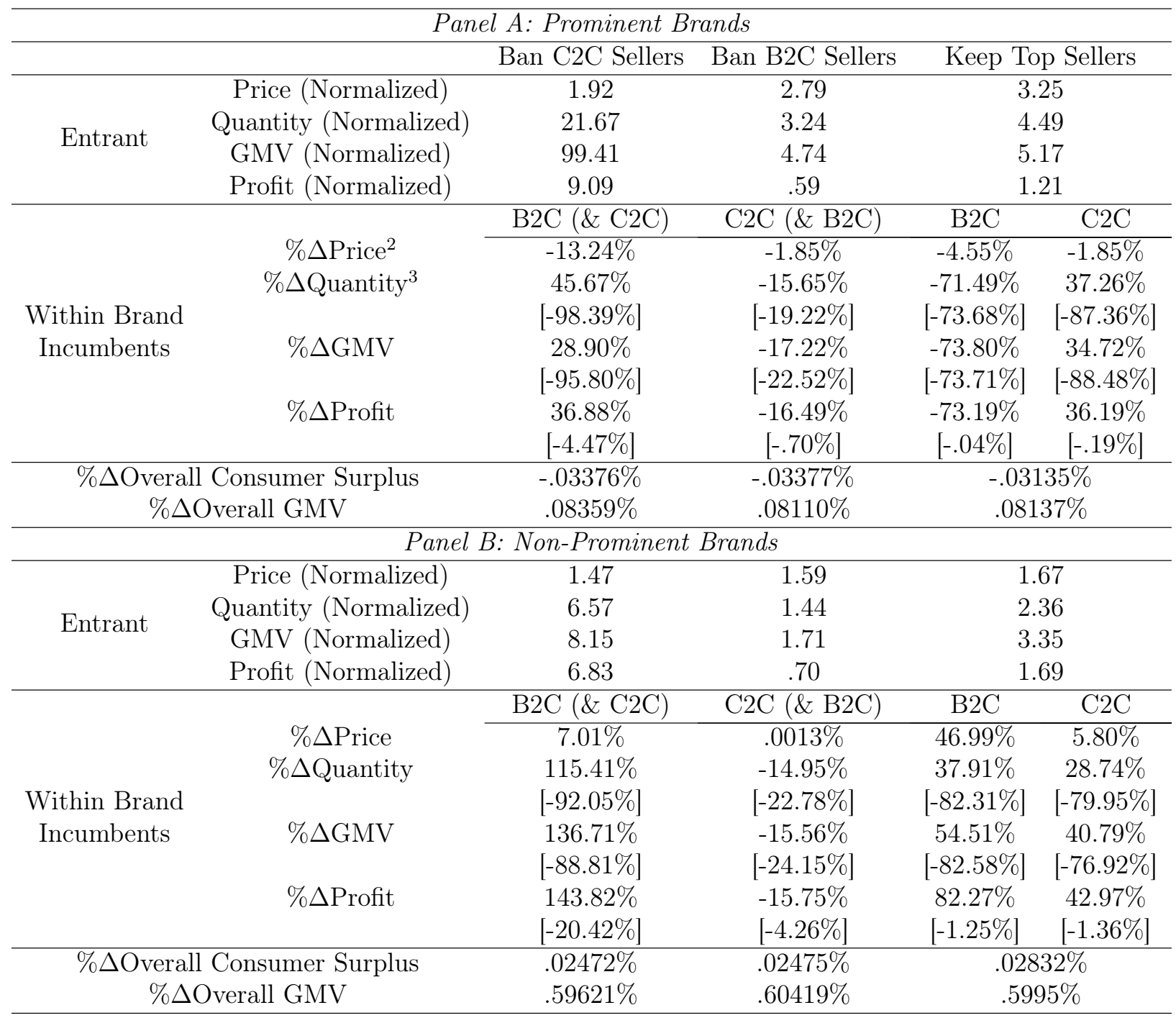

Note: 1 . For each brand (that does not have flagship store), we simulate the entry of its flagship store and calculate the weighted average price changes (across all the products, weighted by GMV) and total quantity/GMV changes. The numbers reported in this table are the averages across these brands. 2. The average relative price change is computed based on the "survived" sellers given the restrictions. 3 . The numbers in the first row are conditioning on "survived" sellers. The numbers in the bracket in the second row are overall "unconditional" changes (for the "Ban C2C Sellers" and "Ban B2C Sellers" cases, this means the total changes in both C2C and $\mathrm{B} 2 \mathrm{C})$. 


\section{Appendix Figures}

Figure 14: Example of A Flagship Store on JD.com

(not necessarily on the platform we study)

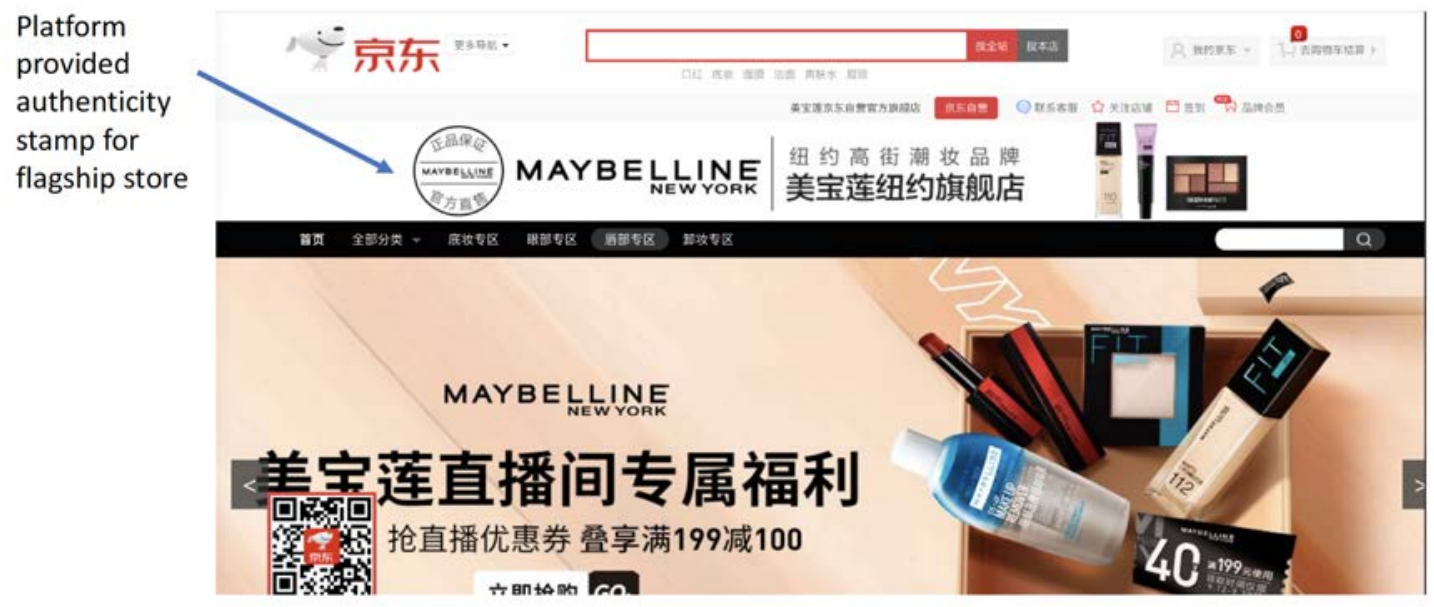

Figure 15: Example of Search Results on JD.com

(not necessarily on the platform we study)

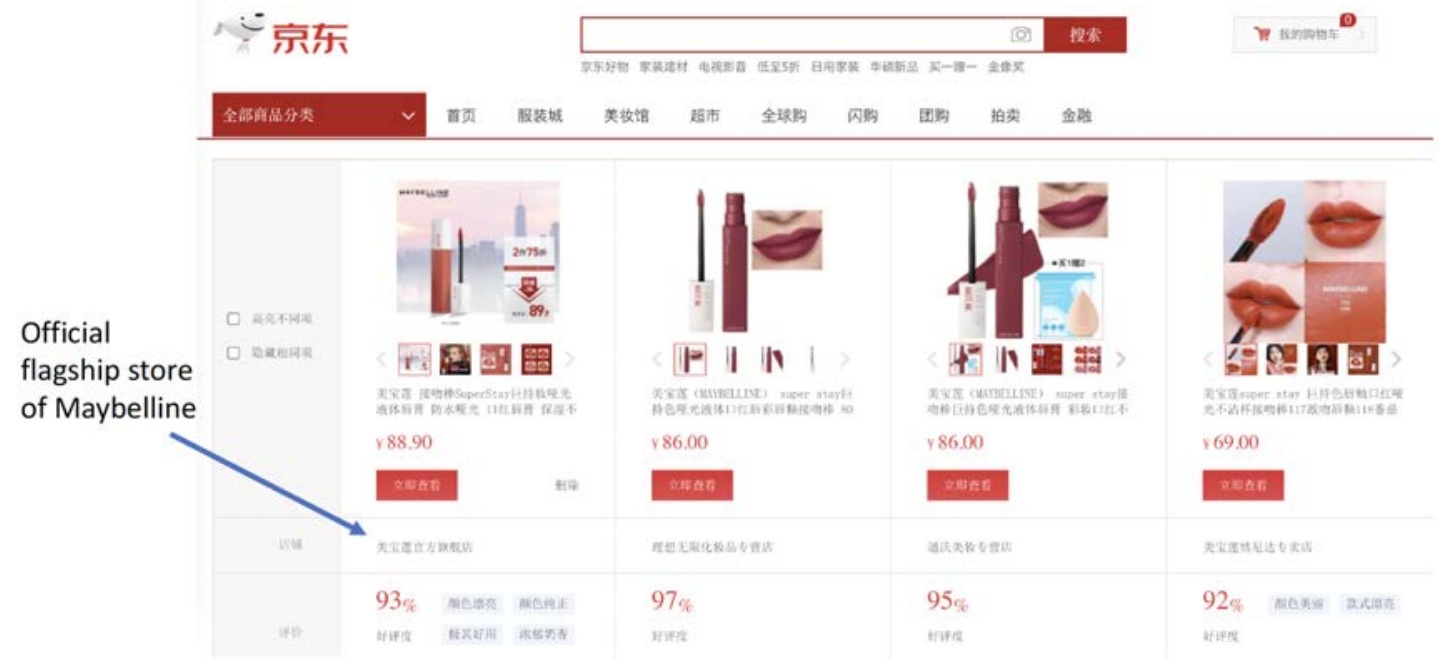


Figure 16: Goodness of Demand Model Fit

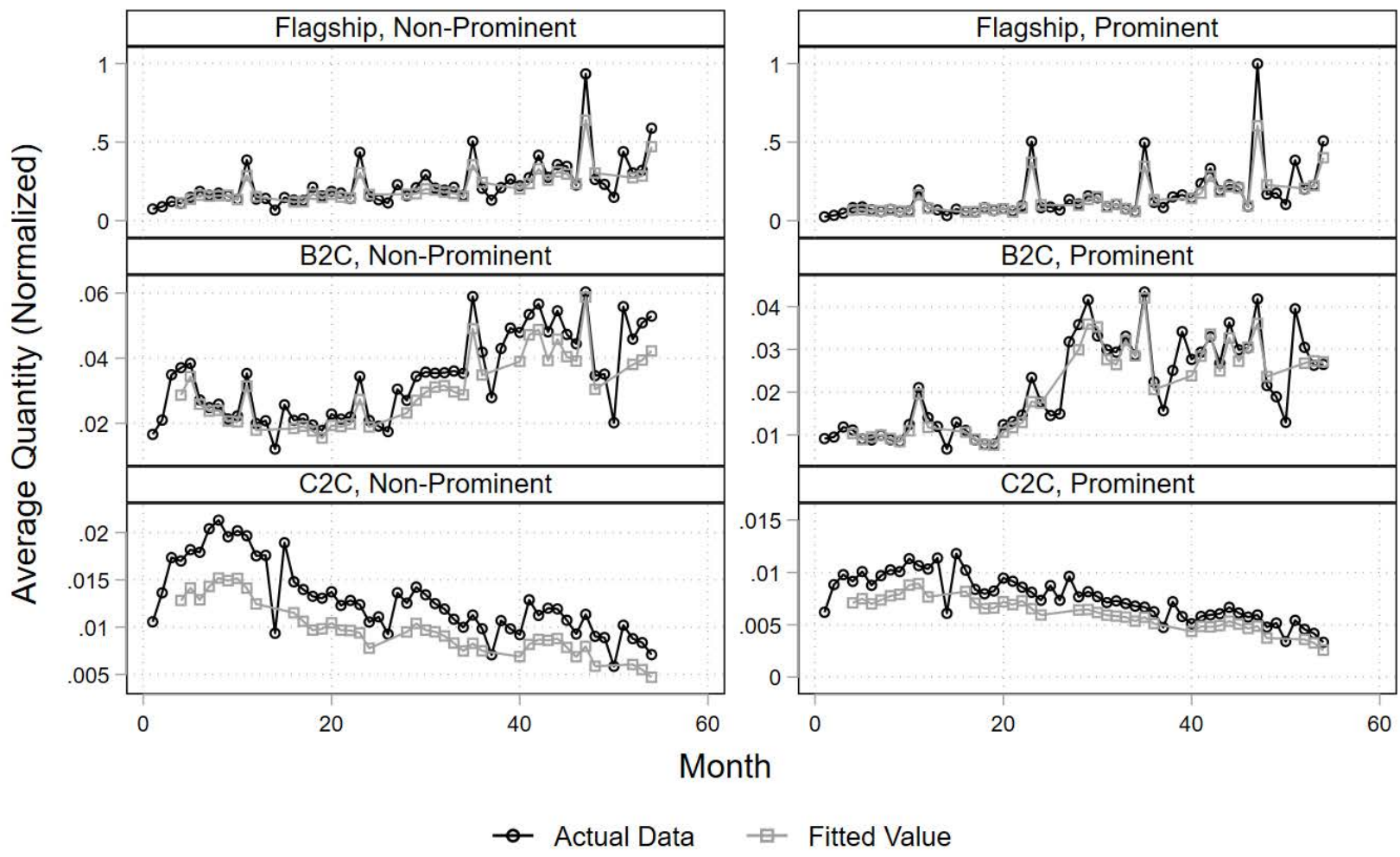

Graphs by Channel and Brand Type 
Figure 17: Correlation with the time of flagship entry

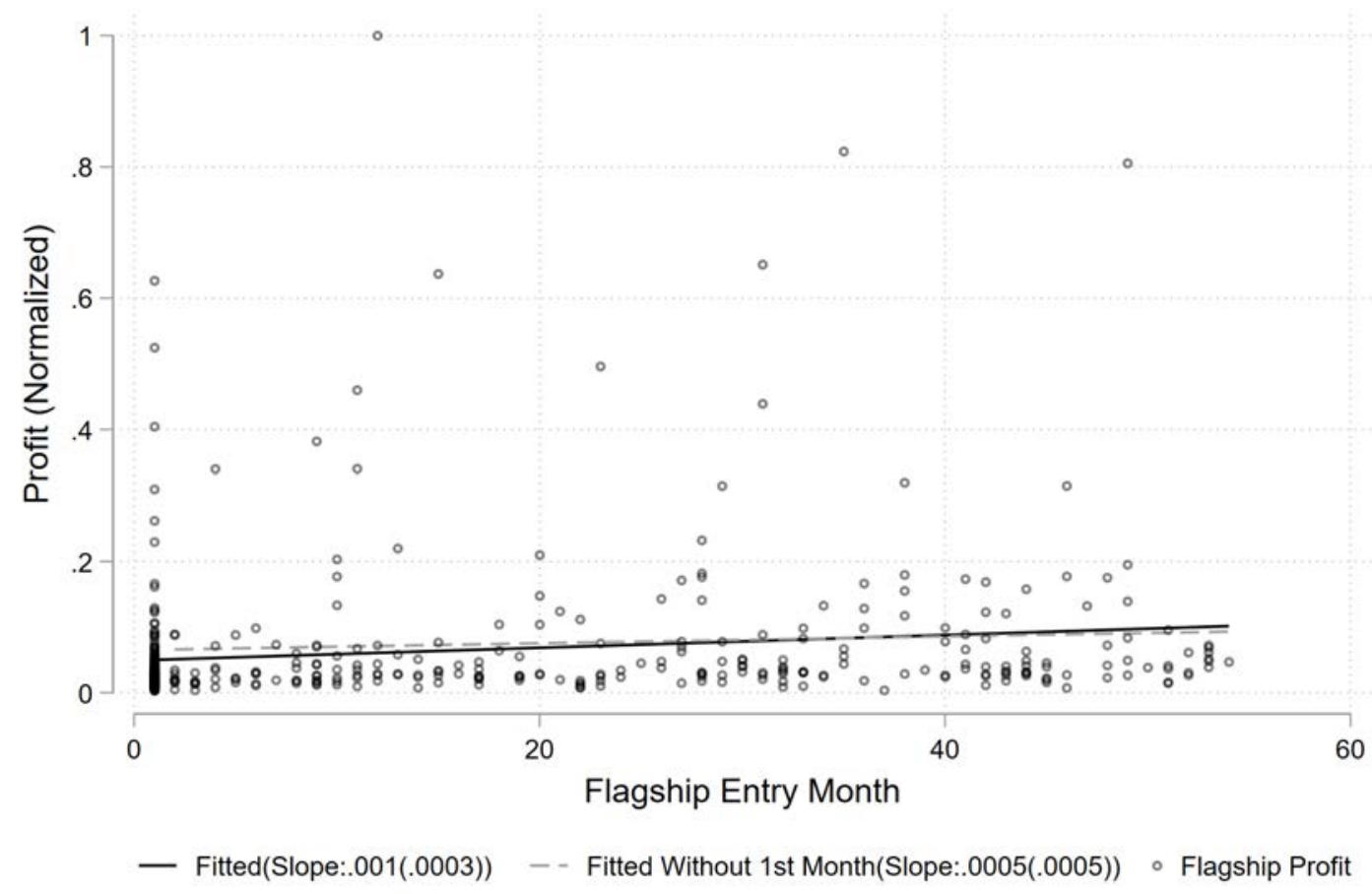

(a) Panel A: Correlation of predicted flagship profits and time of flagship entry

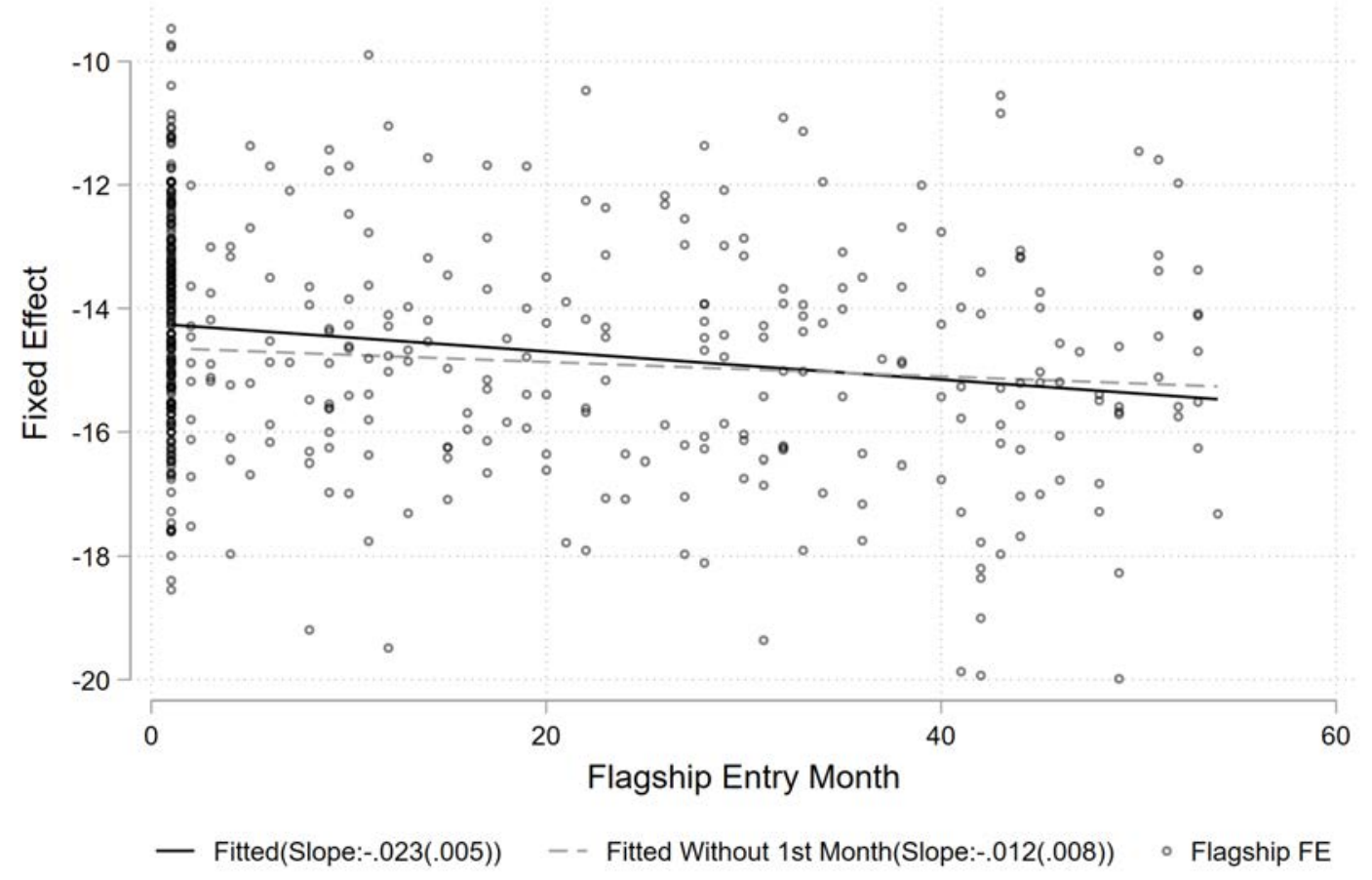

(b) Panel B: Correlation of estimated flagship fixed effects and time of flagship entry 